\title{
A comparative study of land price estimation and mapping using regression kriging and machine learning algorithms across Fukushima prefecture, Japan
}

\author{
DERDOURI Ahmed ${ }^{1}$, MURAYAMA Yuji ${ }^{2}$
}

1. Division of Spatial Information Science, Graduate School of Life and Environmental Sciences, University of Tsukuba, Tennodai, Tsukuba, Ibaraki, Japan;

2. Faculty of Life and Environmental Sciences, University of Tsukuba, Tennodai, Tsukuba, Ibaraki, Japan

\begin{abstract}
Finding accurate methods for estimating and mapping land prices at the macro-scale based on publicly accessible and low-cost spatial data is an essential step in producing a meaningful reference for regional planners. This asset would assist them in making economically justified decisions in favor of key investors for development projects and post-disaster recovery efforts. Since 2005, the Ministry of Land, Infrastructure, and Transport of Japan has made land price data open to the public in the form of observations at dispersed locations. Although this data is useful, it does not provide complete information at every site for all market participants. Therefore, estimating and mapping land prices based on sound statistical theories is required. This paper presents a comparative study of spatial prediction of land prices in 2015 in Fukushima prefecture based on geostatistical methods and machine learning algorithms. Land use, elevation, and socioeconomic factors, including population density and distance to railway stations, were used for modeling. Results show the superiority of the random forest algorithm. Overall, land prices are distributed unevenly across the prefecture with the most expensive land located in the western region characterized by flat topography and the availability of well-connected and highly dense economic hotspots.
\end{abstract}

Keywords: land price; spatial estimation; kriging; machine learning; Fukushima prefecture, Japan

\section{Introduction}

Maps depicting the spatial distribution of land prices are an essential reference in urban and regional planning during post-disaster recovery periods and beyond. Such maps are employed as one of the strategic assets for various purposes, such as optimally allocating land resources (Hu et al., 2016), developing special land policies for potential investors, and making economically justified planning decisions either by planning authorities or ordinary citizens (Cellmer et al., 2014). It is always critical for key investors and planners to investi- 
gate the economic value of land before starting any prospective project at the local and regional levels. However, it is more challenging to examine the variation in land prices in a wide area. This is due to the incredible budget- and time-consuming process behind extracting land price maps covering a whole region, which necessitates costly and lengthy field surveys. Furthermore, the available samples do not usually cover the entire study area in question as the data is collected from dispersed locations. For this reason, a specific spatial analysis is required to estimate land values at any given site.

Geographic Information Systems (GIS) coupled with spatial statistics provide the necessary tools for estimating land prices and extracting accurate maps based on rigorous mathematical models. In recent years, several studies with the objective of estimating and/or mapping land prices have been carried out. However, they differ significantly when it comes to the methodologies followed, the explanatory variables considered, and the spatial scale of the study area selected. Table 1 lists reviewed studies related to the prediction and/or mapping of land and housing prices worldwide, grouped by the implemented estimation approaches that can be split into four categories: (1) hedonic models, (2) geostatistical methods, (3) machine learning algorithms, and (4) hybrid models or multiple approaches compared. Although the relationship between housing prices and land prices has been a controversial topic in terms of the relevant determining factors considered and the statistical models applied (Wen and Goodman, 2013), we present studies that dealt with both.

Table 1 Descriptive list of reviewed literature regarding land price estimation/mapping grouped by estimation approach: (1) hedonic models, (2) geostatistical methods, (3) machine learning algorithms, and (4) comparison of various approaches

\begin{tabular}{|c|c|c|c|c|c|c|}
\hline $\begin{array}{c}\text { Estimation } \\
\text { approach }\end{array}$ & Study & Study area & Method(s) & Mapping & Objective & Highlighted results \\
\hline \multirow{3}{*}{$\begin{array}{l}\text { Hedonic } \\
\text { models }\end{array}$} & (Löchl, 2006) & $\begin{array}{l}\text { Canton Zurich, } \\
\text { Switzerland }\end{array}$ & $\begin{array}{l}\text { Hedonic } \\
\text { regression }\end{array}$ & Yes & $\begin{array}{l}\text { Developing an esti- } \\
\text { mation model of rent } \\
\text { and land prices }\end{array}$ & $\begin{array}{l}\text { Two classified maps } \\
\text { of land prices for } \\
\text { residential and com- } \\
\text { mercial uses }\end{array}$ \\
\hline & $\begin{array}{l}\text { (Kim and Kim, } \\
\text { 2016) }\end{array}$ & $\begin{array}{l}\text { Seoul, South } \\
\text { Korea }\end{array}$ & $\begin{array}{l}\text { OLS and spa- } \\
\text { tial regression } \\
\text { models }\end{array}$ & No & $\begin{array}{l}\text { Estimation of land } \\
\text { value using OLS and } \\
\text { generalized regres- } \\
\text { sion models }\end{array}$ & $\begin{array}{l}\text { Spatial error model } \\
\text { (SEM) found to be the } \\
\text { best of the tested } \\
\text { models }\end{array}$ \\
\hline & $\begin{array}{l}\text { (Hilal et al., } \\
\text { 2016) }\end{array}$ & $\begin{array}{l}\text { Côte-d'Or, } \\
\text { France }\end{array}$ & OLS & No & $\begin{array}{l}\text { Estimation of the } \\
\text { price of agricultural } \\
\text { lands at cadastral } \\
\text { levels based on pre- } \\
\text { vious real estate } \\
\text { transactions }\end{array}$ & $\begin{array}{l}\text { Hedonic prices were } \\
\text { calculated based on a } \\
\text { range of attributes } \\
\text { influencing agricul- } \\
\text { tural lands most nota- } \\
\text { ble time effects }\end{array}$ \\
\hline \multirow{3}{*}{$\begin{array}{l}\text { Geostatistical } \\
\text { methods }\end{array}$} & $\begin{array}{l}\text { (Luo and Wei, } \\
\text { 2004) }\end{array}$ & $\begin{array}{l}\text { Milwaukee, } \\
\text { Wisconsin, USA }\end{array}$ & Kriging & No & $\begin{array}{l}\text { Predicting urban land } \\
\text { values of different } \\
\text { land use categories } \\
\text { using kriging models }\end{array}$ & $\begin{array}{l}\text { Overall average stan- } \\
\text { dard error of } 2 \%\end{array}$ \\
\hline & $\begin{array}{l}\text { (Chica-Olmo, } \\
\text { 2007) }\end{array}$ & $\begin{array}{l}\text { City of Granada, } \\
\text { Spain }\end{array}$ & $\begin{array}{l}\text { Kriging and } \\
\text { cokriging }\end{array}$ & Yes & $\begin{array}{l}\text { Estimating and map- } \\
\text { ping housing prices } \\
\text { using kriging and } \\
\text { cokriging approaches }\end{array}$ & $\begin{array}{l}\text { Cokriging has a lower } \\
\text { standard error com- } \\
\text { pared with that of } \\
\text { kriging }\end{array}$ \\
\hline & $\begin{array}{l}\text { (Inoue et al., } \\
2007 \text { ) }\end{array}$ & $\begin{array}{l}\text { Tokyo } 23 \text { wards, } \\
\text { Japan }\end{array}$ & Kriging & Yes & $\begin{array}{l}\text { Mapping estimated } \\
\text { land prices in To- } \\
\text { kyo's } 23 \text { wards from } \\
1975 \text { to } 2004\end{array}$ & $\begin{array}{l}\text { Kriging model-based } \\
\text { results were more } \\
\text { accurate than those for } \\
\text { OLS with the average } \\
\text { error ranging from } 2 \% \\
\text { to } 10 \%\end{array}$ \\
\hline
\end{tabular}


(Continued)

\begin{tabular}{|c|c|c|c|c|c|c|}
\hline $\begin{array}{c}\text { Estimation } \\
\text { approach }\end{array}$ & Study & Study area & Method(s) & Mapping & Objective & Highlighted results \\
\hline \multirow{4}{*}{$\begin{array}{l}\text { Geostatistical } \\
\text { methods }\end{array}$} & $\begin{array}{l}\text { (Tsutsumi et al., } \\
\text { 2011) }\end{array}$ & $\begin{array}{l}\text { Tokyo metro- } \\
\text { politan area, } \\
\text { Japan }\end{array}$ & $\begin{array}{l}\text { Regression } \\
\text { kriging }\end{array}$ & Yes & $\begin{array}{l}\text { Developing a system } \\
\text { to estimate and map } \\
\text { residential land price } \\
\text { in the Tokyo metro- } \\
\text { politan area }\end{array}$ & $\begin{array}{l}10 \% \text { was the average } \\
\text { error ratio for the } \\
\text { exponential model but } \\
18.3 \% \text { for the Gaus- } \\
\text { sian model }\end{array}$ \\
\hline & $\begin{array}{l}\text { (Kuntz and } \\
\text { Helbich, 2014) }\end{array}$ & $\begin{array}{l}\text { Metropolitan } \\
\text { area of Vienna, } \\
\text { Austria }\end{array}$ & $\begin{array}{l}\text { Kriging and cok- } \\
\text { riging }\end{array}$ & Yes & $\begin{array}{l}\text { Mapping predicted } \\
\text { real estate prices }\end{array}$ & $\begin{array}{l}\text { Universal cokriging } \\
\text { showed better results } \\
\text { in terms of } \\
\text { cross-validation re- } \\
\text { sults }\end{array}$ \\
\hline & $\begin{array}{l}\text { (Chica-Olmo et } \\
\text { al., 2019) }\end{array}$ & $\begin{array}{l}\text { City of Gre- } \\
\text { nada, Spain }\end{array}$ & $\begin{array}{l}\text { Regression and } \\
\text { universal } \\
\text { cokriging }\end{array}$ & Yes & $\begin{array}{l}\text { Spatiotemporally } \\
\text { estimating housing } \\
\text { price variations } \\
1988-2005\end{array}$ & $\begin{array}{l}\text { Regression cokriging } \\
\text { was found to be } \\
\text { slightly better }\end{array}$ \\
\hline & $\begin{array}{l}\text { (Palma et al., } \\
\text { 2019) }\end{array}$ & Italy & Jackknife kriging & No & $\begin{array}{l}\text { Predicting real estate } \\
\text { prices based on } \\
\text { socioeconomic fac- } \\
\text { tors for the period } \\
2014-2016\end{array}$ & $\begin{array}{l}\text { Accuracy of the mod- } \\
\text { el improved when } \\
\text { considering the } \\
\text { spatio-temporal cor- } \\
\text { relation }\end{array}$ \\
\hline \multirow{4}{*}{$\begin{array}{l}\text { Machine } \\
\text { learning al- } \\
\text { gorithms }\end{array}$} & (Gu et al., 2011) & $\begin{array}{l}\text { A district of } \\
\text { Tangshan city, } \\
\text { China }\end{array}$ & $\begin{array}{l}\text { Hybrid genetic } \\
\text { algorithm and } \\
\text { support vector } \\
\text { machine model } \\
\text { (G-SVM), Grey } \\
\text { Model (GM) }\end{array}$ & No & $\begin{array}{l}\text { Forecasting housing } \\
\text { prices }\end{array}$ & $\begin{array}{l}\text { G-SVM outperformed } \\
\text { GM in many aspects }\end{array}$ \\
\hline & $\begin{array}{l}\text { (Antipov and } \\
\text { Pokryshevskaya, } \\
\text { 2012) }\end{array}$ & $\begin{array}{l}\text { Saint Peters- } \\
\text { burg, Russia }\end{array}$ & $\begin{array}{l}\text { Machine learning } \\
\text { algorithms }\end{array}$ & No & $\begin{array}{l}\text { Estimating residen- } \\
\text { tial apartments }\end{array}$ & $\begin{array}{l}\text { Random forest was } \\
\text { found to be the most } \\
\text { robust among all } \\
\text { methods }\end{array}$ \\
\hline & $\begin{array}{l}\text { (Wang et al., } \\
\text { 2014) }\end{array}$ & $\begin{array}{l}\text { Chongqing } \\
\text { city, China }\end{array}$ & $\begin{array}{l}\text { SVM optimized } \\
\text { by particle swarm } \\
\text { optimization } \\
\text { (PSO), BP neural } \\
\text { network }\end{array}$ & No & $\begin{array}{l}\text { Forecasting real } \\
\text { estate price based on } \\
\text { PSO-optimized } \\
\text { SVM compared to } \\
\text { other BP neural } \\
\text { network }\end{array}$ & $\begin{array}{l}\text { PSO-SVM showed } \\
\text { higher forecasting } \\
\text { accuracy than BP } \\
\text { neural network }\end{array}$ \\
\hline & $\begin{array}{l}\text { (Park and Bae, } \\
\text { 2015) }\end{array}$ & $\begin{array}{l}\text { Fairfax County, } \\
\text { Virginia, USA }\end{array}$ & $\begin{array}{l}\text { Machine learning } \\
\text { algorithms (C4.5, } \\
\text { RIPPER, Naïve } \\
\text { Bayesian, and } \\
\text { AdaBoost) }\end{array}$ & No & $\begin{array}{l}\text { Prediction of hous- } \\
\text { ing prices using } \\
\text { different machine } \\
\text { learning methods }\end{array}$ & $\begin{array}{l}\text { RIPPER model out- } \\
\text { performed all selected } \\
\text { methods }\end{array}$ \\
\hline \multirow{4}{*}{$\begin{array}{l}\text { Comparison } \\
\text { of various } \\
\text { approaches }\end{array}$} & $\begin{array}{l}\text { (Bourassa et al., } \\
\text { 2010) }\end{array}$ & $\begin{array}{l}\text { Jefferson } \\
\text { County, } \\
\text { Kentucky, USA }\end{array}$ & $\begin{array}{l}\text { OLS, nearest } \\
\text { neighbors, } \\
\text { geostatistical and } \\
\text { trend } \\
\text { surface models }\end{array}$ & No & $\begin{array}{l}\text { Comparing the out- } \\
\text { comes of several } \\
\text { methods estimating } \\
\text { house prices }\end{array}$ & $\begin{array}{l}\text { The geostatistical } \\
\text { model showed better } \\
\text { results in terms of } \\
\text { prediction errors }\end{array}$ \\
\hline & $\begin{array}{l}\text { (Sampathkumar } \\
\text { et al., 2015) }\end{array}$ & $\begin{array}{l}\text { Chennai met- } \\
\text { ropolitan area, } \\
\text { India }\end{array}$ & $\begin{array}{l}\text { Multiple } \\
\text { regression and } \\
\text { neural network }\end{array}$ & No & $\begin{array}{l}\text { Modeling and esti- } \\
\text { mation of land } \\
\text { prices based on } \\
\text { economic and social } \\
\text { factors }\end{array}$ & $\begin{array}{l}\text { Neural network and } \\
\text { multiple regression } \\
\text { performed well with a } \\
\text { slight superiority of } \\
\text { the former }\end{array}$ \\
\hline & (Hu et al., 2016) & $\begin{array}{l}\text { Wuhan city, } \\
\text { China }\end{array}$ & $\begin{array}{l}\text { Empirical Bayes- } \\
\text { ian kriging } \\
\text { (EBK), GWR, } \\
\text { OLS }\end{array}$ & Yes & $\begin{array}{l}\text { Modeling and visu- } \\
\text { alizing dependency } \\
\text { of urban residential } \\
\text { land price and the } \\
\text { influential variables }\end{array}$ & $\begin{array}{l}\text { Estimated coefficients } \\
\text { of variables impacting } \\
\text { land prices depend on } \\
\text { the location based on } \\
\text { GWR results which } \\
\text { outperformed OLS }\end{array}$ \\
\hline & $\begin{array}{l}\text { (Schernthanner } \\
\text { et al., 2016) }\end{array}$ & $\begin{array}{l}\text { Potsdam, } \\
\text { Germany }\end{array}$ & $\begin{array}{l}\text { Hedonic regres- } \\
\text { sion, kriging, and } \\
\text { random forest }\end{array}$ & Yes & $\begin{array}{l}\text { Comparing esti- } \\
\text { mated rental prices } \\
\text { by three methods } \\
\text { and visualize the } \\
\text { outcome }\end{array}$ & $\begin{array}{l}\text { RF found to be the } \\
\text { most accurate method }\end{array}$ \\
\hline
\end{tabular}


Hedonic modeling is based on the fact that a land parcel or a house is a function of its characteristics (Caplin et al., 2008) and is mostly expressed by a linear regression equation of structural, socioeconomic, and environmental factors. This modeling can be implemented using ordinary least squares (OLS; Crespo and Grêt-Regamey, 2013). It was among the first techniques for evaluating and predicting land or house prices and has long been used by many researchers, including Löchl (2006), Kim and Kim (2016), Bourassa et al. (2010), Schernthanner et al. (2016), and Hilal et al. (2016), among others. These models generally have several limitations because they depend on the availability of a large dataset which has high costs and requires time-consuming field surveys (Kuntz and Helbich, 2014). Following the development of regression modeling techniques, and taking into account the spatial nature of land price observations, other methods have been developed based on spatial autocorrelation and spatial heterogeneity (Crespo and Grêt-Regamey, 2013). Geographically weighted regression (GWR; Brunsdon et al., 1998) is an example of a regression-based method that incorporates the spatial dimension of attributes within the analysis, and many studies showed good results compared to traditional hedonic models. However, when the prediction accuracy of GWR is compared with those of geostatistical methods, many studies have reported low accuracy for GWR compared to that of kriging, for instance (e.g., Kuntz and Helbich, 2014). Kriging and cokriging models have been implemented for different topics in geosciences (e.g., remote sensing, climatology, and agriculture) and have shown robust performance in terms of estimation errors. Due to their flexibility, Palma et al. (2019) affirmed the capability of geostatistical methods to tackle socioeconomic phenomena as well, which can be seen in the number of studies conducted to model land or house rental prices (e.g., Chica-Olmo, 2007; Chica-Olmo et al., 2019; Kuntz and Helbich, 2014; Luo and Wei, 2004; Tsutsumi et al., 2011). Most recently, new studies introduced machine learning (ML) algorithms as possible alternatives to hedonic models and geostatistical methods to describe spatially and temporally the distribution of land prices. Gu et al. (2011), for instance, developed a hybrid model of a genetic algorithm and the random forest (RF) algorithm to forecast housing prices in a Chinese district of Tangshan city. Antipov and Pokryshevskaya (2012) conducted a comparative study of $10 \mathrm{ML}$ methods to estimate residential apartments in St. Petersburg. A similar study was carried out by Park and Bae (2015) to model housing prices in Fairfax County (in the United States) by comparing various ML algorithms. Other efforts have been made to empirically compare the performance of two or more approaches among different ML, hedonic, and geostatistical techniques. For example, Bourassa et al. (2010) compared the house prices estimation results of OLS, a two-stage nearest neighbors' residual procedure, geostatistical methods, and trend surface models based on around 13,000 transactions from Louisville, Kentucky. According to the authors, the geostatistical approach based on the robust exponential mathematical model performed best. In a similar vein, Sampathkumar et al. (2015) investigated land price trends by employing multiple regression and neural networks to model land prices in the Indian Metropolitan Area of Chennai. They found that both approaches performed well; the second method was slightly better. Schernthanner et al. (2016) used hedonic regression, kriging, and the random forest algorithm to map the estimated rental prices in the German city of Potsdam. The authors concluded that the RF algorithm is the most accurate method for forecasting and mapping land prices in the region. 
Overall, comparative spatial studies on estimation of land prices across a macro-area implementing geostatistical methods and ML algorithms are scarce. Moreover, most of the papers used different datasets for each approach, which may lead to data-dependent results. Additionally, most studies did not map the spatial distribution of price estimation and consequently, missed helpful, informative statistics in a given study area. The present study may contribute considerably to the increasing academic works on land prices by filling these research gaps, as it aims at empirically comparing the outcome of three mathematical models of regression kriging and nine of the most frequently used ML algorithms. Specifically, this paper addresses the following objectives: (1) mapping the estimated land prices using regression kriging and empirically assessing the outcomes, (2) mapping the predicted land prices using nine different ML algorithms and empirically evaluating the results, and (3) qualitatively and quantitatively comparing the results of the two approaches.

The remainder of this paper is structured as follows. In Section 2, light is shed on land price estimation and mapping in Japan. In Section 3, the study area and the spatial estimation techniques used are introduced, an overview of the data sources and the explanatory variables considered is provided, the methodological framework is presented. In Section 4, the results of the different analyses are provided and compared. In Section 5, the results and limitations of the study are discussed, and the conclusions are presented.

\section{Background of land price estimation and mapping in Japan}

In Japan, land is a precious natural resource, as the archipelagic country has limited flat areas and has been experiencing fast urban expansion for decades. Several factors influence the land price, including population density, proximity to economic hotspots (e.g., central business district (CBD)), accessibility to means of transportation and geophysical characteristics (e.g., location, topography, and land use). In general, most of these factors are related to urban growth. Capozza and Helsley (1989), among others (e.g., Arnott and Lewis, 1979; Capozza et al., 1986), confirmed that there is a positive proportional relationship between the speed of urban growth and land prices.

Moreover, as one of the most natural disaster-prone countries in the world, Japan is continuously involved in post-disaster reconstruction and redevelopment plans in affected regions. These plans necessitate developing special land policies based on economically justified decisions supported by accurate references, such as land price maps assessing existing assets to encourage potential infrastructure investments, for instance. Therefore, land price is an important key for allocating land resources for wise regional and urban planning and development, specifically in big cities and metropolitan areas characterized by recurrent changes in population and infrastructures ( $\mathrm{Hu}$ et al., 2016). For these reasons, monitoring land prices has become a priority issue for decision-makers and under intensive investigation and analysis by academic researchers. In the Japanese context, spatial data for land prices is published every year by local and prefectural governments. Although this data may be downloaded free of charge from the internet, it is available only as GIS vector points and in a limited number of samples, which does not provide complete information for all market participants (Inoue et al., 2007). Because of this limitation, developing an approach for accurately estimating and mapping land prices in all locations across a given study area based 
on rigorous statistical principles is needed. Many estimation methods have been used separately, including geostatistics-based models and machine learning algorithms. However, comparative analyses that investigate the methods with precise results are relatively scarce.

There have been many empirical studies with the aim of estimating land prices in Japan, focusing mainly on the Tokyo Metropolitan Area (TMA). For instance, Shimizu and Nishimura (2007) employed a hedonic approach based on OLS to develop commercial and residential land price indices for the core wards of the TMA, and then to investigate the structural changes in land pricing between 1975 and 1999 reflecting the pre-bubble, bubble, and post-bubble periods. The authors found differences in price structure due to location and fluctuations between supplier pricing and end-user preferences. Using the same estimation approach, Sasaki and Yamamoto (2018) estimated hedonic residential prices in the TMA by introducing "regional vulnerability" and "accessibility to destination stations" as two new explanatory variables. To the extent of our knowledge, however, only two English-language papers with the aim of mapping estimated land prices using GIS were published. The first study was conducted by Inoue et al. (2007) in which the authors used universal kriging to estimate land prices in Tokyo's 23 wards spatially and temporally over 30 years (from 1975 to 2004). By comparing kriging results with those of the OLS model, the authors found that the former performed better, with an estimation error ranging from $2 \%$ to $10 \%$ except during the period from 1986 to 1991 (approximately 20\%) when the Japanese economy experienced harsh stagnation due to the fall in land prices and the stock price bubble (Shimizu et al., 2015). The second study was carried out by Tsutsumi et al. (2011) in which they developed a computer-aided system that combines GIS and statistical theories to extract land price maps of the TMA based on free officially published residential land price observations. Regression kriging was used in the study, where two mathematical models of semi-variograms (exponential and Gaussian) were employed. The results showed that the exponential model performed better with a $10 \%$ average error ratio; the ratio was $18.3 \%$ for the Gaussian model. This study was a useful reference for the present paper, mainly in terms of the selection of explanatory variables and the regression kriging analysis.

\section{Materials and methods}

\subsection{Study area}

The study area is Fukushima prefecture (Figure 1) located in the Tohoku region, Japan. The prefecture is divided into seven subregions (Aizu, Iwaki, Minamiaizu, Kenchu, Kennan, Kenpoku, and Soso). According to the Ministry of Internal Affairs and Communications, approximately $1,914,000$ residents live in an area of $13,784 \mathrm{~km}^{2}$ with a total population density of 140 residents per square kilometer (MIAC, 2016). The region is characterized by a mountainous landscape mainly in the western region predominantly in Minamiaizu with the elevation ranging between 0 and $2333 \mathrm{~m}$ above sea level. Major cities, which are well connected by railways and highways, are located in flat areas primarily in the coastal areas of Iwaki and Soso; the central region located in Kenpoku, Kenchu, and Kennan; and in the northeast region of the prefecture specifically in the Aizu subregion. Following the 2011 Fukushima Daiichi accident, the prefectural government designated nuclear-contaminated areas as evacuation zones (Figure 1). These areas, located mainly in Soso and Kenpoku, are 
divided into three zones according to radiation levels and authorized entry, business operations, and resident levels. Generally, previous residents are prohibited from living in all zones with some exceptions in areas labeled as "restricted residence zone" and "evacuation-order cancellation preparation zone." However, business operations are fully permitted in the outer zone, but are partially granted in the restricted-residence zone.

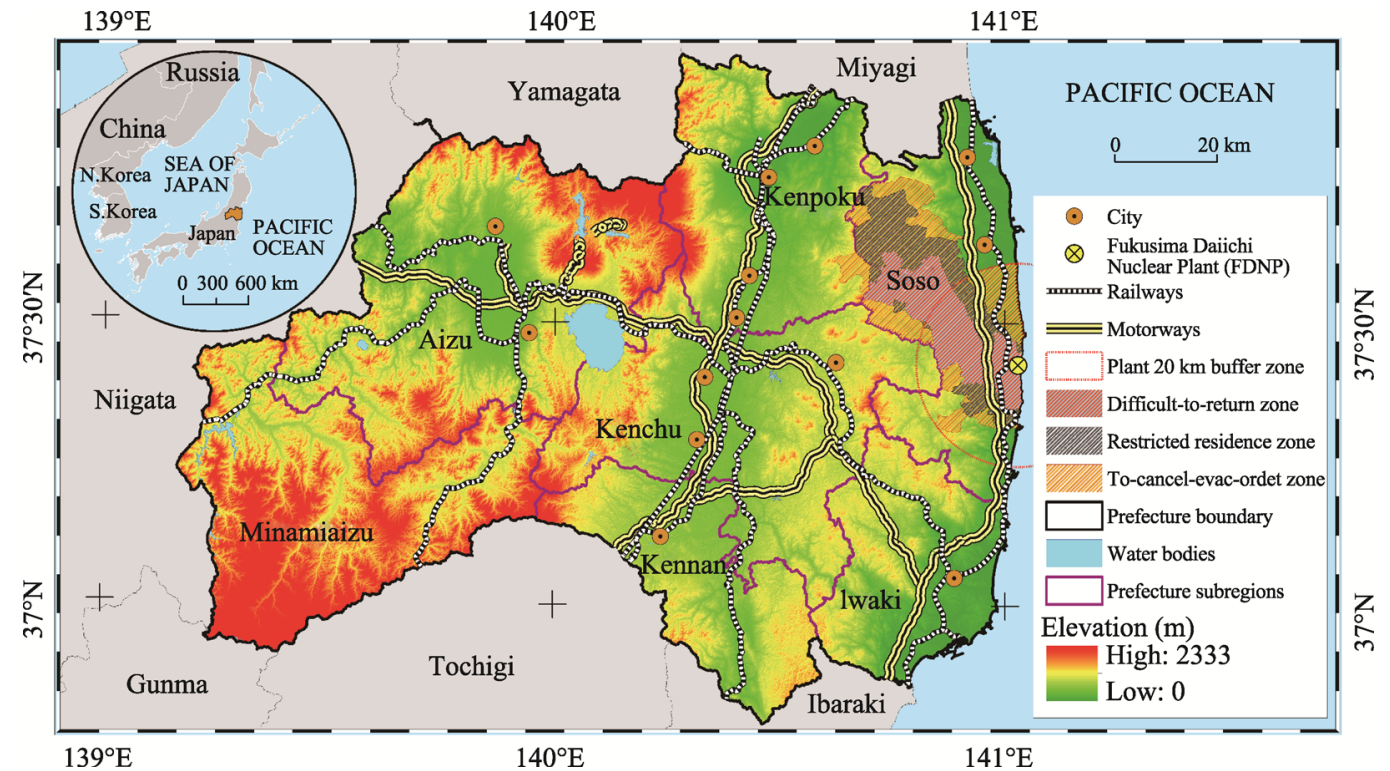

Figure 1 Fukushima prefecture and its administrative boundaries, topographic features, transportation lines, and evacuation zones after the Fukushima Daiichi Nuclear Plant disaster (as of September 2015)

Since the disastrous accident at the Fukushima Daiichi Nuclear Plant in the aftermath of the Great Earthquake of 2011, public opposition to nuclear power has intensified in Japan generally, and in Fukushima prefecture in particular given that it was the most affected prefecture (Tsujikawa et al., 2016). This fact forced the prefectural government to rely more on clean energy resources to improve energy security (Wang et al., 2016), as part of a promising vision to become renewable energy self-sufficient by 2040 (Derdouri and Murayama, 2018).

Consequently, the prefectural government and interested investors are looking for optimal locations in the prefecture to develop renewable energy projects (e.g., solar, wind, and hydro). However, for this site suitability exercise to be achieved, various evaluation criteria including "land price" are required. For instance, in a study carried out by Tegou et al. (2010) in which they evaluated the suitability of wind power plants on the Greek island of Lesvos, the authors considered the criterion "land value" to estimate the economic value of the area, among other factors. Likewise, Derdouri and Murayama (2018) extracted the map of the ideal sites for installing new wind parks in Fukushima prefecture. The authors, through a survey among local wind experts and different stakeholders, concluded that the evaluation factor "land price" is among the five most important criteria in the suitability analysis of wind farms in the prefecture. Therefore, the prefecture of Fukushima was selected as the study area of the present study.

The prefecture has been the center of national and even global attention since 2011. Mul- 
tiple studies on the effects of the 2011 nuclear disaster on land prices were carried out. Yamane et al. (2013), Tanaka and Managi (2016), and Kawaguchi and Yukutake (2017) concluded that soil contamination resulted from the accident caused land prices to fall. However, these studies analyzed only short-term impacts. In contrast, Nishimura and Oikawa (2017) examined the long-term effects of the accident on land prices in the prefecture and areas surrounding nuclear reactors in Japan and found that the impacts are not significant. This is shown in Figure 2 illustrating the average values of land prices by land category from 2005 to 2018 in the prefecture based on local and prefectural governments' observation surveys. Before 2011, commercial, residential, and industrial land parcels had experienced continuous slight decreases in value since 2005 by around $16,230 \mathrm{JPY} / \mathrm{m}^{2}, 6340 \mathrm{JPY} / \mathrm{m}^{2}$, and 5492 $\mathrm{JPY} / \mathrm{m}^{2}$, respectively. However, forest land, which represents the most valuable type of land in the prefecture, with an average price of $143,200 \mathrm{JPY} / \mathrm{m}^{2}$ in 2005 , lost approximately $44,067 \mathrm{JPY} / \mathrm{m}^{2}$ of its value from 2005 to 2011 . The cost of these types of land dropped sharply after the 2011 earthquake, losing another $8839 \mathrm{JPY} / \mathrm{m}^{2}$ by 2012. In contrast, minor drops in values were observed for the other types of land post-earthquake. Starting in 2013, we can see the prices for all types are generally steady with an observed slight decrease in the value of forest land compared to a small increase in the value of commercial, residential, and industrial land. Overall, from a historical perspective, the 2011 Fukushima Daiichi accident caused land prices to drop for a short period until 2013. Then these values stabilized with slight changes during the following years.

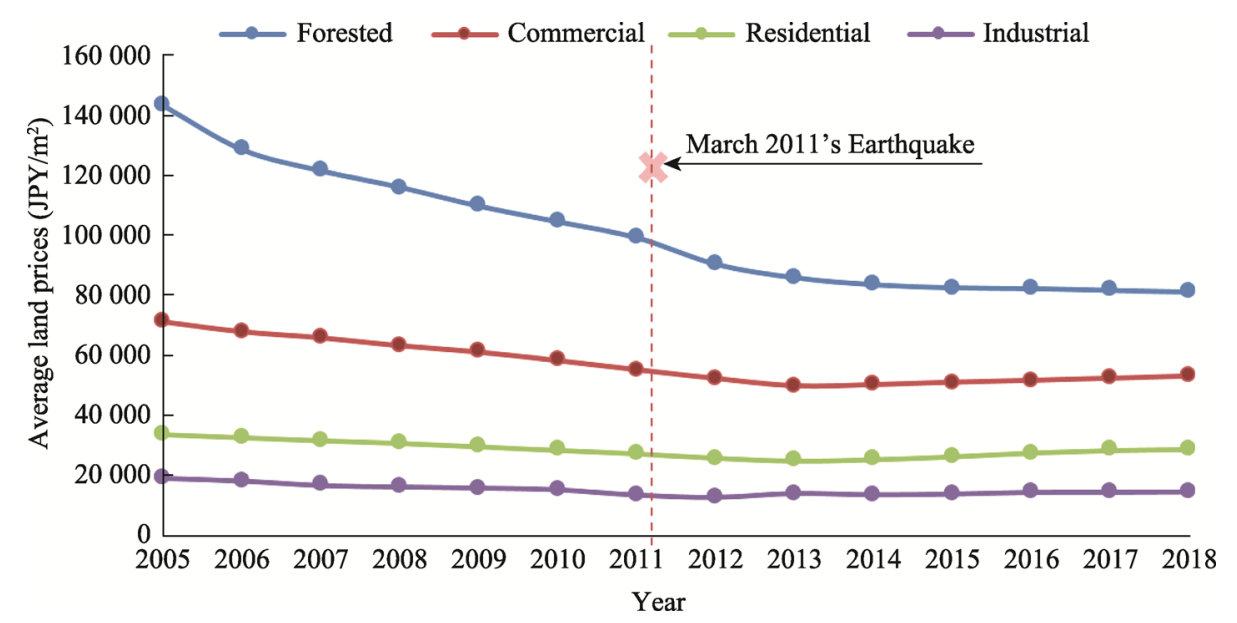

Figure 2 Changes in land prices averaged by land type in Fukushima prefecture (2005-2018)

\subsection{Spatial estimation techniques}

The interpolation methods proposed in this research are divided into two groups: geostatistical and machine learning based. The former refers to kriging, which is a widely applied method for interpolation developed by South African statistician Danie G. Krige (Krige, 1951) in the early 1950s. It deals with spatial correlations to compute the best linear unbiased predictor values at any unobserved location by relying on observed values of explanatory variables. The latter is a collection of algorithms that train machines to detect possible correlations in observations' data. Tables 2 and 3 summarize the spatial estimation methods used in this study in addition to the R packages used for every model. The R geostat package (Pebesma, 
2004) was used to perform kriging, whereas the caret package (Kuhn, 2008) was employed to implement machine learning methods. More details about these techniques are found in the following sections.

Table 2 The three mathematical models used for kriging and their abbreviations

\begin{tabular}{ccccc}
\hline \multicolumn{2}{c}{ Model } & & Abbreviation & R package \\
\hline \multirow{3}{*}{ Geostatistical } & \multirow{3}{*}{ Universal kriging } & Exponential & krig.EXP & \\
& & Gaussian & krig.GAU & gstat (Pebesma, 2004) \\
& & Spherical & krig.SPH & \\
\hline
\end{tabular}

Table 3 Summary of spatial prediction models used in this study: Linear, nonlinear, and regression trees models are grouped as proposed by Kuhn and Johnson (2013). Abbreviations are used to refer to each method in the manuscript

\begin{tabular}{|c|c|c|c|}
\hline Category & Model & Abbreviation & R package \\
\hline \multirow{3}{*}{ Linear } & Generalized linear model & $G L M$ & base \\
\hline & Generalized additive model using splines & GAMS & mgcv \\
\hline & Support vector machines with linear kernel & SVMLinear & kernlab \\
\hline \multirow{3}{*}{ Nonlinear } & Multivariate adaptive regression spline & $M A R S$ & earth \\
\hline & k-nearest neighbors & $k N N$ & base \\
\hline & Support vector machines with radial basis function kernel & SVMRadial & kernlab \\
\hline \multirow{3}{*}{$\begin{array}{l}\text { Regression } \\
\text { trees }\end{array}$} & Cubist & Cubist & Cubist \\
\hline & Stochastic gradient boosting & $G B M$ & gbm (Ridgeway, 2005) \\
\hline & Random forest & $R F$ & randomForest (Breiman, 2001) \\
\hline
\end{tabular}

\subsubsection{Regression kriging}

The first spatial estimation technique is regression kriging (Hengl, 2009; Hengl et al., 2007). The idea of multiple linear regression is to find the best linear equation that describes the relationship between two or more explanatory variables and the response variable. In this case, these variables are in the form of geographic data, and the following linear model is used to estimate the land price at any location:

$$
y_{s}=\beta_{0}+\sum_{i=1}^{N} \beta_{i} x_{i, s}+\varepsilon_{s}
$$

where $s$ refers to each location, and $y_{s}$ is the value of the response variable, which in this case is the land price value at location s. Due to the skewed distribution of the land price values, we decided to work with the $\log 10$-transformed values instead. In addition, $i$ denotes the index of the explanatory variables; its values are within the range $(1,2 \ldots N)$ where $N$ is the total number of explanatory variables considered. $\beta_{0}$ and $\beta_{i}$ are the parameters of the regression line. $x_{i, s}$ represents the values of the explanatory variables at location $\mathrm{s}$. $\varepsilon_{s}$ is the residuals of the regression model.

Kriging employs semi-variograms which are functions measuring the strength of the spatial correlation as a function of distance based on Tobler's first law of geography that everything is related to everything else, but near things are more related than distant things (Tobler, 1970). The semi-variogram is described in the following equation: 


$$
\gamma(h)=\frac{1}{2 N(h)} \sum_{i=1}^{N(h)}\left[z\left(s_{i}+h\right)-z\left(s_{i}\right)\right]^{2}
$$

where $N$ is the number of pairs of sample points separated by distance $h, z\left(s_{i}\right)$ is the value of the target variable at some sampled location, and $z\left(s_{i}+h\right)$ is the value of the neighbor at distance $s_{i}+h$.

The three mathematical models, namely, exponential, Gaussian, and spherical, represented by equations (3), (4), and (5), respectively, are used to fit the semi-variogram to the curve to the empirical data of land prices. Consequently, the important characteristics (i.e., sill, range, and nugget) are determined for each model:

$$
\begin{gathered}
\gamma(h)=\left\{\begin{array}{cl}
c_{0}+c\left(1-\exp \left(\frac{-h}{r}\right)\right) & h>0 \\
0 & h=0
\end{array}\right. \\
\gamma(h)=\left\{\begin{array}{cl}
c_{0}+c\left(1-\exp \left(\frac{-h^{2}}{r^{2}}\right)\right) & h>0 \\
0 & h=0
\end{array}\right. \\
\gamma(h)=\left\{\begin{array}{cc}
c_{0}+c\left(\frac{3 h}{2 \alpha}+\frac{1}{2}\left(\frac{h}{\alpha}\right)^{3}\right) & 0<h \leqslant \alpha \\
c_{0}+c & h>\alpha \\
0 & h=0
\end{array}\right.
\end{gathered}
$$

To evaluate the performance of the models, validation and cross-validation are applied using root mean squared error (RMSE), which is a widely used formula to measure the error rate of a regression model. The following equation represents the RMSE:

$$
R M S E=\sqrt{\frac{\sum_{i=1}^{n}\left(\hat{y}_{i}-y_{i}\right)^{2}}{n}}
$$

where $\hat{y}_{i}$ and $y_{i}$ represent the predicted and real values, respectively, and $n$ is the total number of validation points.

\subsubsection{Machine learning}

Machine learning is a collection of mathematics-, computation- and statistics-based methods that aim to automatically learn rules and dependencies from examples and data (Ratle et al., 2010). In this study, we considered the nine machine learning algorithms listed in Table 3. These models can be classified into three categories following Kuhn and Johnson's (2013) proposition: (1) linear, (2) nonlinear, and (3) regression trees.

The three models of the first category are the generalized linear model (GLM), generalized additive model using splines (GAMS), and support vector machines with linear kernel (SVMLinear). They are practical in linear relationships between the dependent variable and covariates, and they seek to find estimated coefficients that minimize the sum of the squared errors. These models can be interpreted easily by analyzing the estimated coefficients. Moreover, due to the ability to compute standard errors, the significance of every covariate can be deduced. However, from a real-world perspective, they oversimplify complex prob- 
lems especially in the case of limited covariates.

Nonlinear models include multivariate adaptive regression spline (MARS), k-nearest neighbors $(k N N)$, and support vector machines with radial basis function kernel (SVMRadial). In contrast to linear models, these models do not require knowing the form of the relationship between the dependent variable and explanatory variables beforehand.

The third category comprises tree-based models, including Cubist (Cubist), stochastic gradient boosting $(G B M)$, and random forest $(R F)$. They are considered nonlinear models as well; however, they were categorized in a separate group due to their wide popularity. These models split the data into partitions based on one or more nested conditional statements [If ... Then] according to the predictor values. Subsequently, for each partition, the outcome is determined.

\subsection{Explanatory variables and data sources}

Land value can be affected by various variables. According to Wen et al. (2018), these variables are frequently grouped into three types: (1) individual factors referring to the characteristics of the land parcel such as size and shape; (2) neighborhood factors related to the characteristics of the land parcel including socioeconomic variables, external environment, and amenities; and (3) location determinants depicting traffic patterns and distance to the CBD. In the literature, multiple authors have associated the economic value of land with variables such as population density, proximity to railways, schools, and other facilities. For example, Zhuang and Zhao (2014) analyzed the effects of land use and railway stations on land prices in Fukuoka city of Japan concluding that land prices near railway stations and commercial or industrial hotspots are usually high. The closer the land to these locations, the expensive it becomes. Likewise, Kanasugi and Ushijima (2018) examined the impacts of a scheduled-to-open high-speed railway on residential land prices. The authors reported an increase in land prices in the areas that shortened travel time to the TMA. Kok et al. (2014) examined the determinants of land prices in the metropolitan area of the San Fransisco Bay Area. Results indicated that elevation and job density among other geographic, topographic, and demographic factors, are strongly associated with land economic values. Tsutsumi et al. (2011) linked land prices in the TMA with population density and land use, among other factors. Adegoke (2014) investigated the factors determining the value of residential properties in the Ibadan metropolis in Nigeria. Adegoke found a significant relationship between land price and mainly the population density and level of development. Other studies have linked proximity to urban facilities, such as schools, parks, and sports-related venues with mainly residential prices in Singapore (Murakami, 2018), China (Liu et al., 2007), Kuwait (Mostafa, 2018), Spain (Chica-Olmo et al., 2019), and the United States (Clapp et al., 2008; Espey and Owusu-Edusei, 2001; Kiel and Zabel, 2008). In conclusion, the selection process of suitable factors depends mainly on various elements, such as the setting of the designated target area, type of land price (e.g., residential and commercial), and the availability of aspatial or spatial data.

In this study, we based the selection of explanatory variables on the literature by considering the following elements: (1) the land parcels are within urban and rural areas, (2) the land parcels are not only for residence purposes, and (3) the availability of free spatial data satisfying two necessary conditions in accordance with the following (Tsutsumi et al., 2011). First, 
the corresponding spatial data of each explanatory variable should cover the whole prefecture of Fukushima, so that the estimated land price can be calculated at any location within the study area. Second, the data should have been collected during the same year as much as possible (i.e., 2015). Table 4 shows the final list of the explanatory variables, where the column heading "Data" indicates the sources of data listed in Table 1, and "GIS function" refers to the ArcMap's function that was used to extract the variable values from the data.

Table 4 List of explanatory variables selected in this study with their data sources and the related abbreviations

\begin{tabular}{|c|c|c|c|c|}
\hline Explanatory variables & Data & GIS function & Variable description & Abbreviation \\
\hline $\begin{array}{l}\text { Distance to the nearest railway sta- } \\
\text { tion (m) }\end{array}$ & $\begin{array}{l}\text { Railway } \\
\text { stations }\end{array}$ & Near & $\begin{array}{l}\text { Calculated using the railway } \\
\text { stations layer }\end{array}$ & Distance \\
\hline Area of rice fields $\left[\mathrm{m}^{2}\right]$ & & & & Paddy \\
\hline Area of other agricultural land $\left(\mathrm{m}^{2}\right)$ & & & & Agricultural \\
\hline Area of forests $\left(\mathrm{m}^{2}\right)$ & & & & Forests \\
\hline Area of uncultivated land $\left(\mathrm{m}^{2}\right)$ & & & The areas of different land-uses & Uncultivated \\
\hline Area of roads $\left(\mathrm{m}^{2}\right)$ & & & within one square kilometer & Roads \\
\hline Area of railways $\left(\mathrm{m}^{2}\right)$ & in a & Spatial Join & classified according to the $\mathrm{Na}$ - & Railways \\
\hline Area of other land uses $\left(\mathrm{m}^{2}\right)$ & $\begin{array}{l}\text { square } \\
\text { kilometer }\end{array}$ & & tional Land Numerical Informa- & Other uses \\
\hline Area of water bodies $\left(\mathrm{m}^{2}\right)$ & & & & Water \\
\hline Area of seashore $\left(\mathrm{m}^{2}\right)$ & & & & Seashore \\
\hline Area of the surface of the sea $\left(\mathrm{m}^{2}\right)$ & & & & Sea \\
\hline Area of golf courses $\left(\mathrm{m}^{2}\right)$ & & & & Golf \\
\hline $\begin{array}{l}\text { Dummy variable for urbanization } \\
\text { promoting area }\end{array}$ & $\begin{array}{l}\text { Promoted } \\
\text { urbaniza- } \\
\text { tion areas }\end{array}$ & Spatial Join & $\begin{array}{l}\text { A dummy variable; if the point } \\
\text { location falls inside the area, the } \\
\text { variable value receives } 1 \text {, else } 0\end{array}$ & Promotion \\
\hline Population density (persons $/ \mathrm{km}^{2}$ ) & Population & Spatial Join & $\begin{array}{l}\text { Calculated using the population } \\
\text { data of } 2015 \text { for every minor } \\
\text { municipal district }\end{array}$ & Density \\
\hline Number of enterprises & Enterprises & Snatial Join & Statistical GIS data of 2015 for & Enterprises \\
\hline Number of employees & Employees & Spatıal Joln & every minor municipal district & Employees \\
\hline Elevation (m) & DEM & $\begin{array}{l}\text { Extract Multi } \\
\text { Values to Points }\end{array}$ & Elevation of the point location & Elevation \\
\hline
\end{tabular}

The present study exploits publicly available and no-cost data from different sources. Data on published and prefectural land price observations of the year 2015 was downloaded from the National Land Numerical Information download service ${ }^{1}$ (Ministry of Land, Infrastructure, Transport, and Tourism) as GIS vector data. Other data layers were obtained from the same source, including railway stations, promoted urbanization areas, and a grid of 1 $\mathrm{km}^{2}$ cells containing information about the area of every land use. Data on population of 2015 census, number of enterprises, and employees of every minor municipal district was collected from the Statistics Bureau of Japan ${ }^{2}$. Finally, a digital elevation model (DEM) was downloaded using EarthExplorer of USGS ${ }^{3}$. Table 5 summarizes the data used in this analysis and describes the sources of the data and the year of release.

\subsection{Methodological framework}

The proposed methodology for this analysis is illustrated in Figure 3. It consists of three parts: (1) data preparation using GIS software ArcGIS, (2) geostatistical analysis employing the software RStudio (https://www.rstudio.com/), and (3) machine learning modeling using

\footnotetext{
${ }^{1}$ National Land Numerical Information download service. URL: http://nlftp.mlit.go.jp/ksj-e/gml/gml_datalist.html (in English)

${ }^{2}$ Statistical GIS - Portal site for Japanese Government Statistics. URL: https://www.e-stat.go.jp/gis (in Japanese)

${ }^{3}$ United States Geological Survey. URL: https://earthexplorer.usgs.gov/
} 
RStudio. A detailed explanation of every part is given in the following sections.

Table 5 Overview of datasets used in the study, their sources, and the year of release

\begin{tabular}{lcc}
\hline \multicolumn{1}{c}{ Data layers } & Source & Year \\
\hline Land price observations (published and prefectural) & & 2015 \\
Railway stations & National Land Numerical & 2015 \\
Land uses within $1 \mathrm{~km}^{2}$ area and their areas & Information & 2014 \\
Promoted urbanization areas & 2011 \\
\hline Population of every minor municipal district & Statistics Bureau of Japan & 2015 \\
Number of enterprises and employees of every minor municipal district & & USGS \\
\hline DEM & & - \\
\hline
\end{tabular}
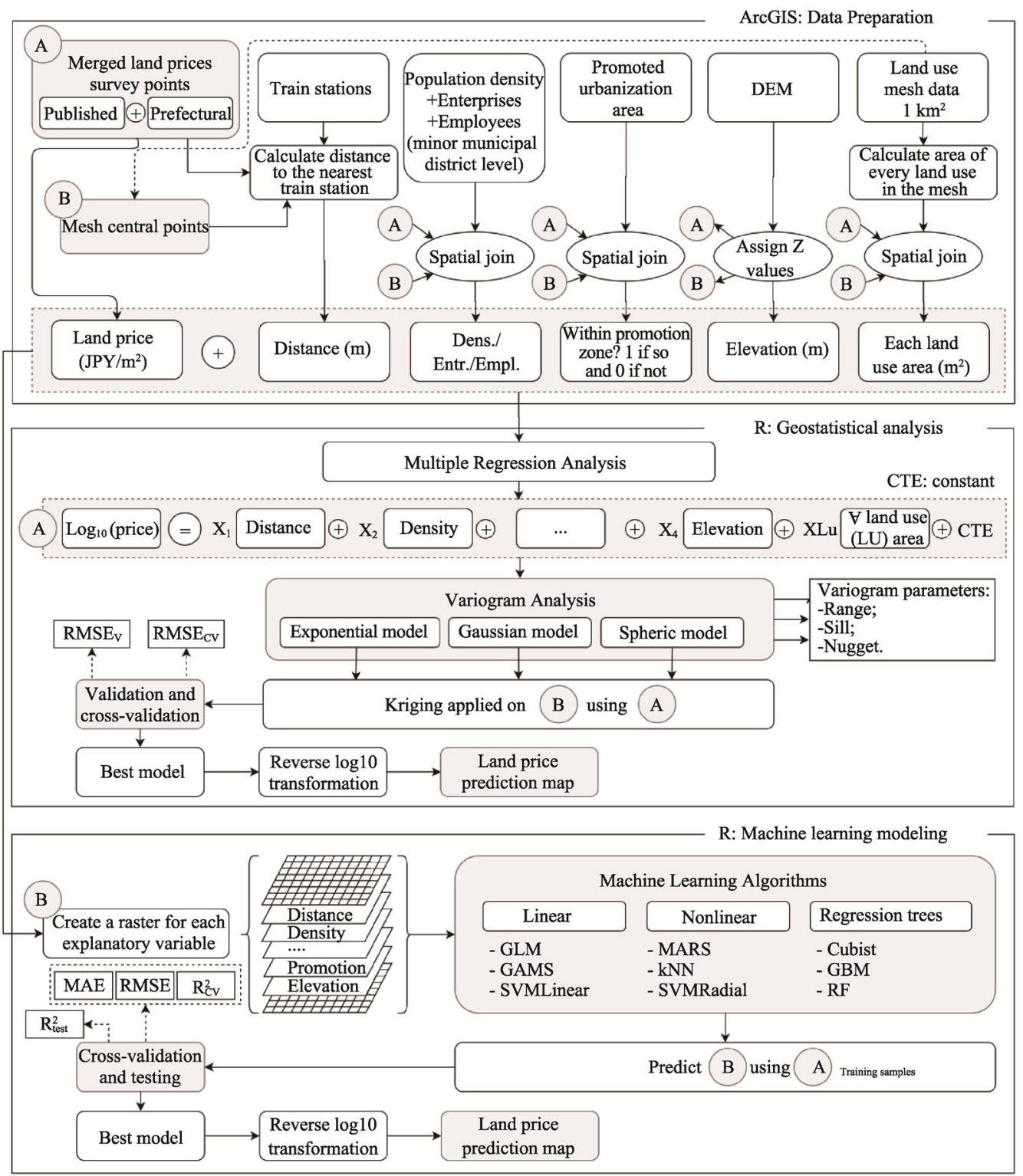

Figure 3 Methodological framework of the study 
Data preparation: The first part consists of preparing a points-data layer A and points grid B. The former contains the merged observations of land prices (resulted from published and prefectural observation surveys) covering the extent of the study area, including the six neighboring prefectures: Miyagi, Yamagata, Niigata, Gunma, Tochigi, and Ibaraki. The extent of the study area was considered in this analysis to include more observation points and to make them distributed all over Fukushima prefecture as shown in Figure 4. The latter is the layer of the central points of a $1 \mathrm{~km}^{2}$ cell mesh where the horizontal distance between every two points is about $1100 \mathrm{~m}$, and the vertical distance is approximately $900 \mathrm{~m}$. Layer A and grid B contain the same fields representing the explanatory variables, including the distance to the nearest railway station, population density, elevation, surface of every land use within an area of $1 \mathrm{~km}^{2}$, and a field representing whether a point falls within the promoted urbanization zone or not. For every point of A and B, the values of these explanatory variables are extracted using the Near, Spatial Join, and Extract Multi Values to Points functions in ArcMap.

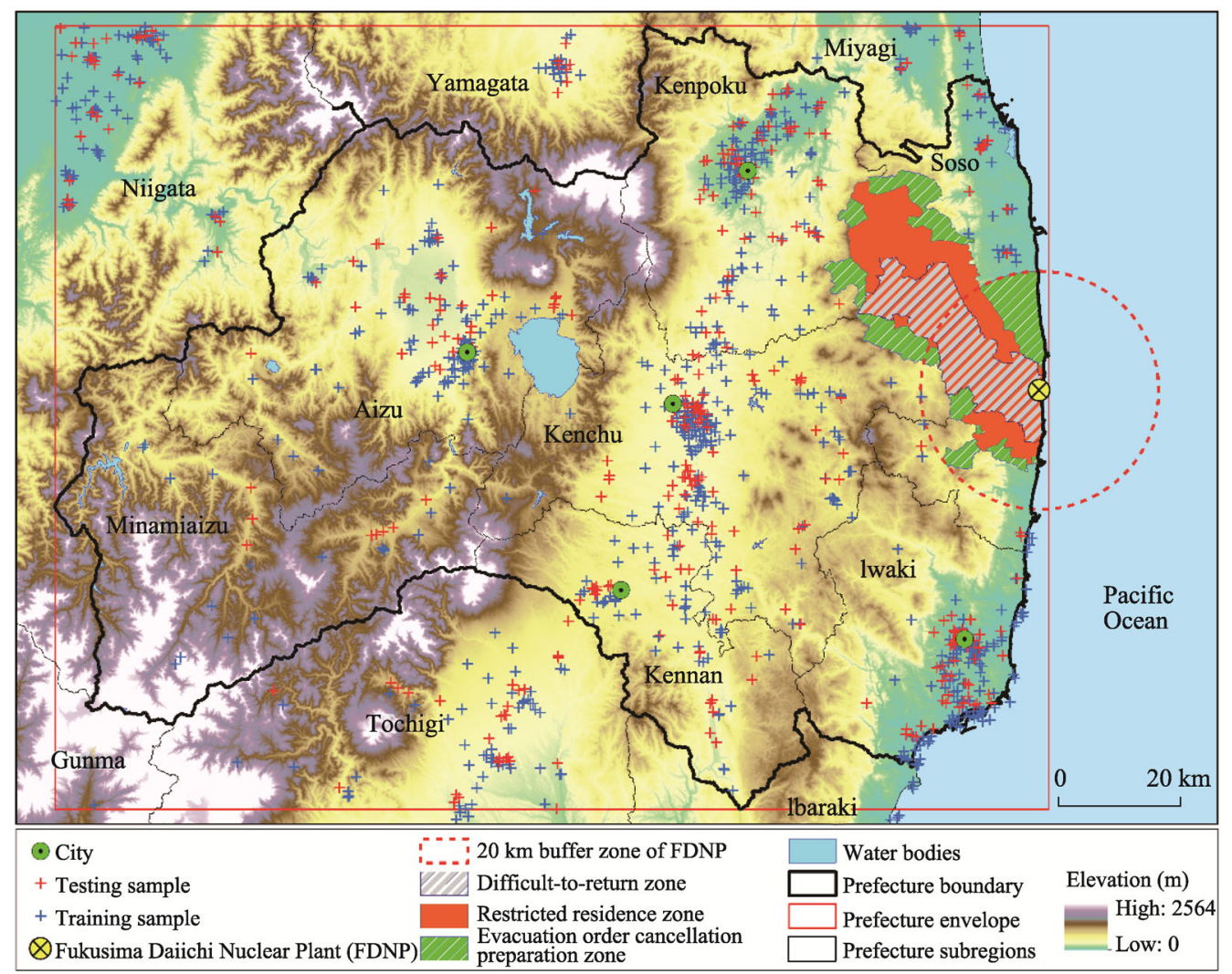

Figure 4 The distribution of land price samples in the study area

Geostatistical analysis: This part includes a two-step procedure which is regression kriging. Based on Matheron's theory, a regionalized variable can be modeled as a sum of two components: deterministic and stochastic (Szymanowski et al., 2013). First, multiple regression analysis is applied with the assumption that the dependent variable (log-transformed land prices) is spatially correlated with a collection of explanatory vari- 
ables in which their values are known at every location in the study area. Second, as explained in Section 3.2.1, we use three mathematical models (exponential, Gaussian, and spherical) to fit the variogram. Consequently, we use the fitted semi-variogram for every model to predict the values log-transformed land prices at all points of grid B. We then perform validation and cross-validation to assess the accuracy of the results of the three models by calculating the RMSE.

Machine learning modeling: The last part of the analysis consists of running machine learning methods using R's caret library. By applying the ArcMap function Point to Raster on grid B, rasters representing explanatory variables are created. Thirteen machine learning algorithms are applied. We randomly split the observation samples into training samples $(70 \%)$ and testing samples (30\%). To compare the performance of these methods, the same training and testing samples were used for both approaches.

\section{Results}

\subsection{Regression analysis}

Before the geostatistical analysis and machine learning modeling were carried out, linear regression analysis was performed to find the relationship between selected explanatory variables and the independent variable (i.e., log-transformed land prices). Table 6 lists the regression parameters and their estimates calculated using the generalized least-square

Table 6 Regression results with detailed explanatory variables and their estimated coefficients

\begin{tabular}{|c|c|c|c|}
\hline Variables & Unit & Coefficients' estim & \\
\hline Intercept & - & 4.439 & $* * *$ \\
\hline Distance to the nearest railway station & $\mathrm{m}$ & $-2.09 \times 10^{-5}$ & $* * *$ \\
\hline Population density & persons $/ \mathrm{km}^{2}$ & $3.104 \times 10^{-5}$ & $* * *$ \\
\hline Area of rice fields & $\mathrm{m}^{2}$ & $-3.935 \times 10^{-7}$ & $* * *$ \\
\hline Area of other agricultural land & $\mathrm{m}^{2}$ & $-4.731 \times 10^{-7}$ & $* * *$ \\
\hline Area of forests & $\mathrm{m}^{2}$ & $-2.733 \times 10^{-7}$ & $* * *$ \\
\hline Area of uncultivated land & $\mathrm{m}^{2}$ & $-7.437 \times 10^{-7}$ & . \\
\hline Area of roads & $\mathrm{m}^{2}$ & $7.211 \times 10^{-7}$ & $* *$ \\
\hline Area of railways & $\mathrm{m}^{2}$ & $-3.301 \times 10^{-8}$ & \\
\hline Area of other land uses & $\mathrm{m}^{2}$ & $-8.97 \times 10^{-8}$ & \\
\hline Area of water bodies & $\mathrm{m}^{2}$ & $-3.086 \times 10^{-7}$ & $* * *$ \\
\hline Area of seashore & $\mathrm{m}^{2}$ & $-1.922 \times 10^{-6}$ & \\
\hline Area of the surface of the sea & $\mathrm{m}^{2}$ & $-1.25 \times 10^{-7}$ & \\
\hline Area of golf courses & $\mathrm{m}^{2}$ & $-5.843 \times 10^{-8}$ & \\
\hline Dummy variable for urbanization promoting area & - & $1.819 \times 10^{-1}$ & $* * *$ \\
\hline Elevation & $\mathrm{m}$ & $-1.556 \times 10^{-4}$ & $* *$ \\
\hline Number of enterprises & - & $3.363 \times 10^{-4}$ & $* *$ \\
\hline Number of employees & - & $-2.951 \times 10^{-5}$ & $*$ \\
\hline
\end{tabular}

Number of samples $=1092$; residual standard error $=0.1683$, multiple $R^{2}=0.7408$, adjusted $R^{2}=0.7349$;

F-statistic $=125.7, \mathrm{p}$-value $=<2.2 \times 10^{-16}$

$* * *=$ sign. at $1 \%$ level $* *=$ sign. at $5 \%$ level 
method. As expected, the coefficients of "population density," "area of roads," "area of railways," and "dummy variable for urbanization promoting area" are positive. However, those for "distance to the nearest station" and "elevation" are negative, because the price of land decreases when the land is farther away from the nearest railway station or when the land is located in a mountainous area.

Regarding the accuracy of the regression model, the output F-statistic $=190.1$ (p-value $<$ $2.2 \times 10^{-16}$ ) indicates that we should reject the null hypothesis that the explanatory variables collectively do not affect land prices. The adjusted $R^{2}$ refers to the total percentage of sample points explained by the regression model. In this case, the total variation in the land price of about $73 \%$ of the points is explained by the explanatory variables.

\subsection{Geostatistical analysis}

For the geostatistical analysis, three mathematical models were used to perform kriging. Figure 5 illustrates the final corresponding fitted semi-variograms. All three models have nugget and sill values that are relatively equal to 0 ; however, the range of the krig.SPH model $(1438 \mathrm{~m})$ is approximately two times the krig.EXP's $(644 \mathrm{~m})$ and the krig.GAU's (760 m).
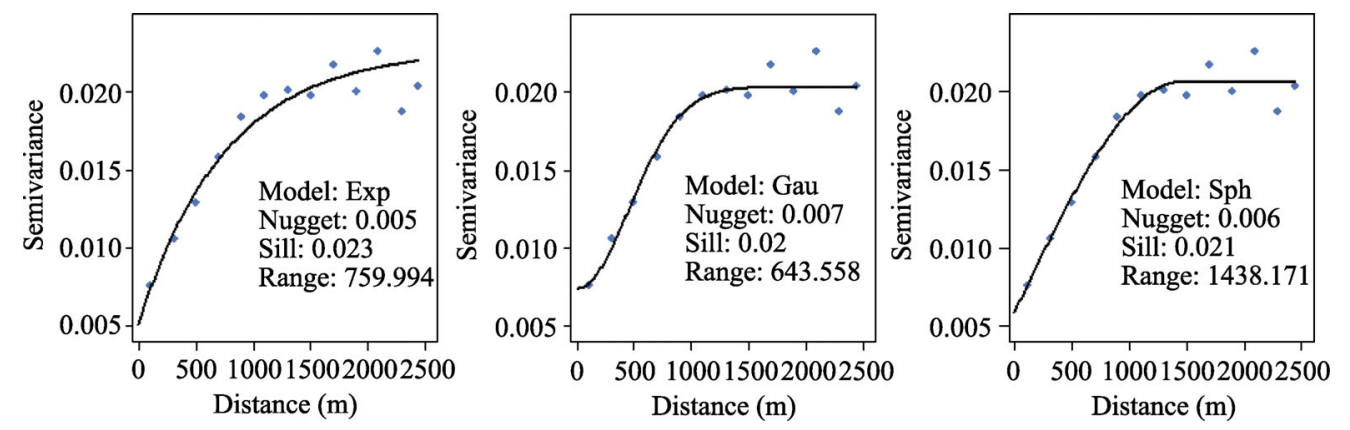

Figure 5 Fitted semi-variograms for the kriging models for the year 2015: (a) Exp: Exponential (b) Gau: Gaussian (c) Sph: Spherical. The nugget, range, and sill values and the mathematical models are shown in the bottom right corner

Figure 6 shows the results of the regression kriging using exponential, Gaussian, and spherical models, respectively. The maps on the left present the prediction results of log-transformed land prices, whereas the maps on the right show their validation errors. The validation error maps show that land price values were underestimated within urban areas $(<$ $10 \mathrm{~km}$ ) mainly in Fukushima, Koriyama, and Iwaki cities. However, the prices were overestimated outside the urban domain $(>10 \mathrm{~km})$. These fluctuations may be attributed to many possible reasons: (1) the high density of observation points within urban areas and the low density elsewhere, (2) the broad study area, and (3) the use of a single model to predict prices within and outside urban areas.

The accuracy of the results of the kriging models was evaluated using validation and cross-validation approaches. Table 7 shows the RMSE values calculated using both methods. The models' prediction errors are relatively equal, which range approximately between $15.1 \%$ and $15.9 \%$ for validation and cross-validation. The exponential model gives slightly 
better outcomes in both tests, which coincide with the result found by Tsutsumi et al. (2011) as well as Chica-Olmo et al. (2019). Figure 7 shows the land price maps for the year 2015 compiled based on officially published observational data.
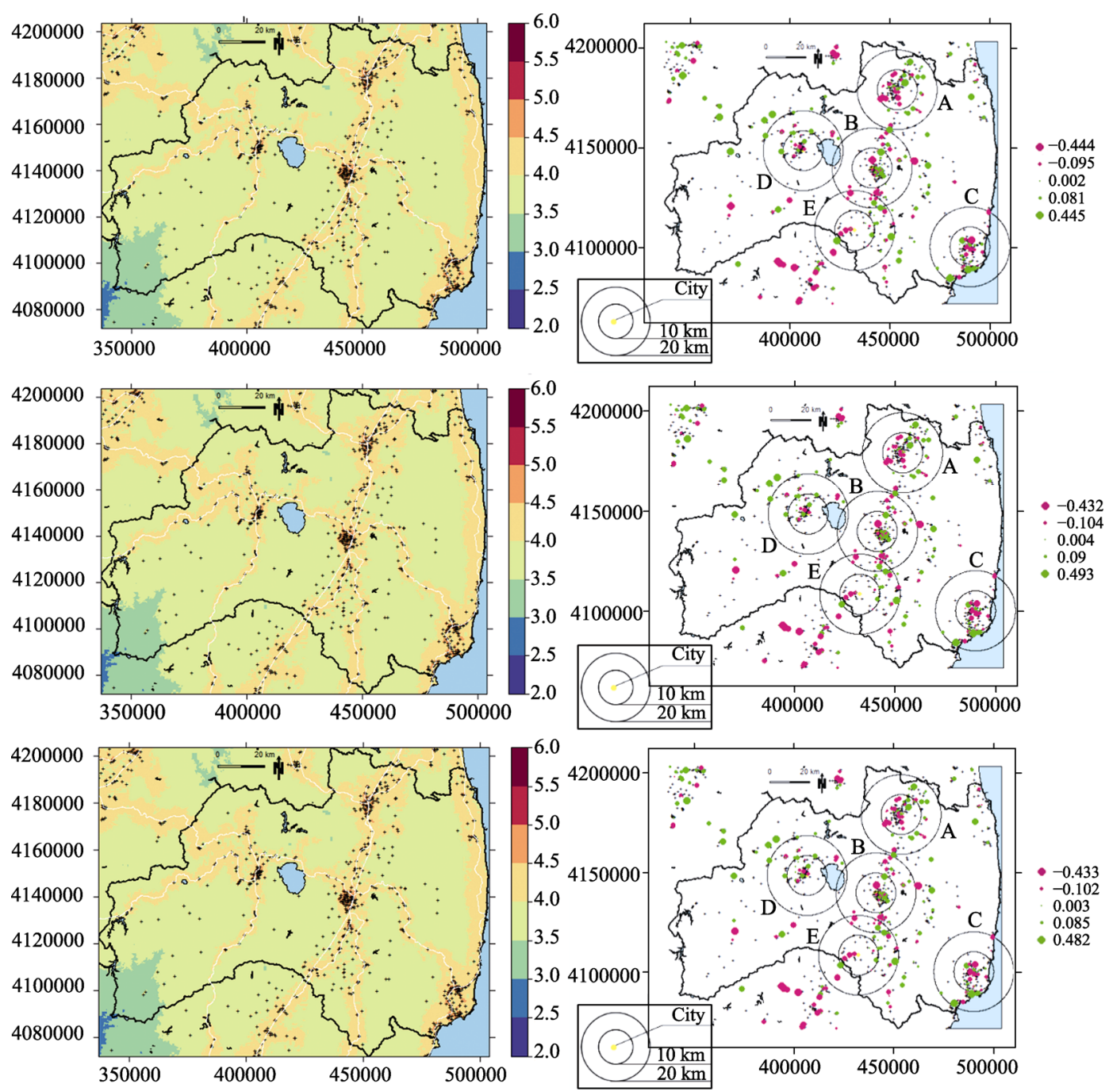

Figure 6 The results of the regression kriging for the year 2015 using the exponential model (upper), Gaussian model (middle), and spherical model (lower). On the left are the estimated log-transformed land prices using regression kriging. On the right are the validation errors in the training samples. Capital letters denote major cities within Fukushima prefecture, which are A: Fukushima, B: Koriyama, C: Iwaki, D: Aizuwakamtsu, and E: Shirakawa

Table 7 Prediction errors of validation and cross-validation tests for the three kriging models

\begin{tabular}{ccc}
\hline \multirow{2}{*}{ Mathematical models } & Validation & Cross-validation \\
\cline { 2 - 3 } & $\operatorname{RMSE}_{\mathrm{V}}(\%)$ & RMSE $_{\mathrm{CV}}(\%)$ \\
\hline Exponential & 15.32 & 15.1 \\
Gaussian & 15.86 & 15.57 \\
Spherical & 15.57 & 15.5 \\
\hline
\end{tabular}




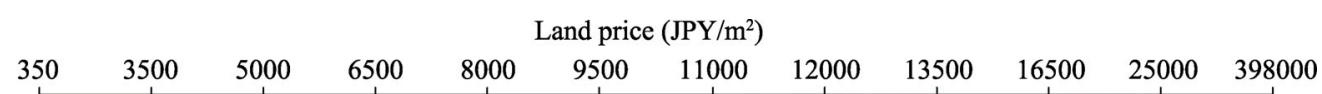

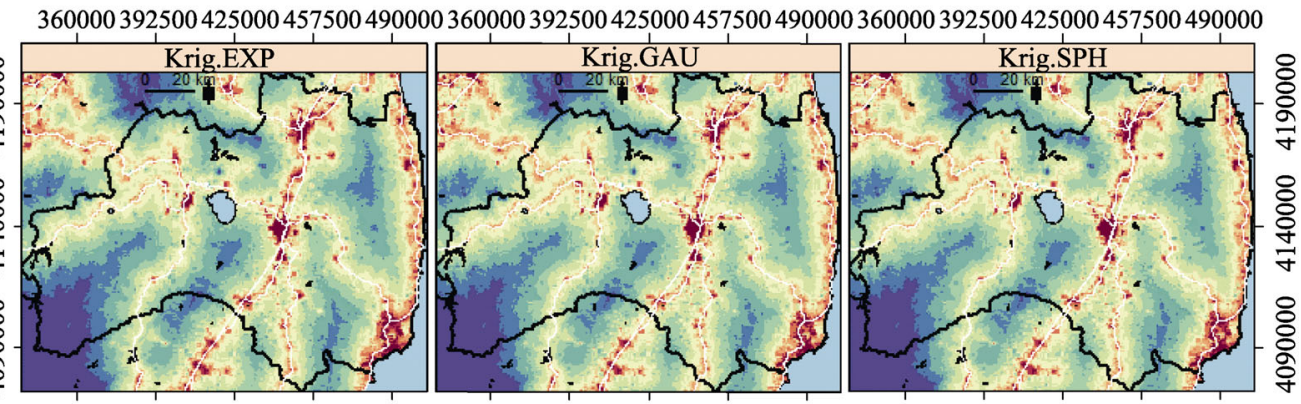

360000392500425000457500490000360000392500425000457500490000360000392500425000457500490000

Figure 7 Land price maps for the year 2015 predicted from officially published land price observations using regression kriging based on three mathematical models (ordered from left to right): (1) Krig.EXP: Exponential model, (2) Krig.GAU: Gaussian model, and (3) Krig.SPH: Spherical model

\subsection{Machine learning modeling}

The performance of the nine machine learning methods was assessed in terms of the mean absolute error (MAE), the RMSE and $\mathrm{R}^{2}$. Additionally, testing samples were used to calculate the overall accuracy of the methods (Figure 8 and Table 8). The different performance indicators generally show good values for both validation tests. For 10-fold cross-validation, the MAE ranges from $11.39 \%$ to $13.50 \%$, the RMSE from $15.37 \%$ to $17.35 \%$ and $\mathrm{R}^{2}\left(\mathrm{R}_{\mathrm{CV}}^{2}\right)$ from $72.24 \%$ to $79.17 \%$. Using the testing samples, $\mathrm{R}^{2}\left(\mathrm{R}_{\text {test }}^{2}\right)$ was calculated which has values ranging between $59.12 \%$ and $77.68 \%$. The results indicate that these values are lower than $\mathrm{R}_{\mathrm{CV}}^{2}$, and the difference ranges between $1.49 \%$ and $13.61 \%$. Among these methods, $\mathrm{RF}$ seems to be the most robust method in terms of all performance indicators in agreement with the conclusions of Antipov and Pokryshevskaya (2012). Moreover, it can be found that regression tree algorithms generally score better results than nonlinear and linear methods as their RMSE values are above $70 \%$ in both validation tests.
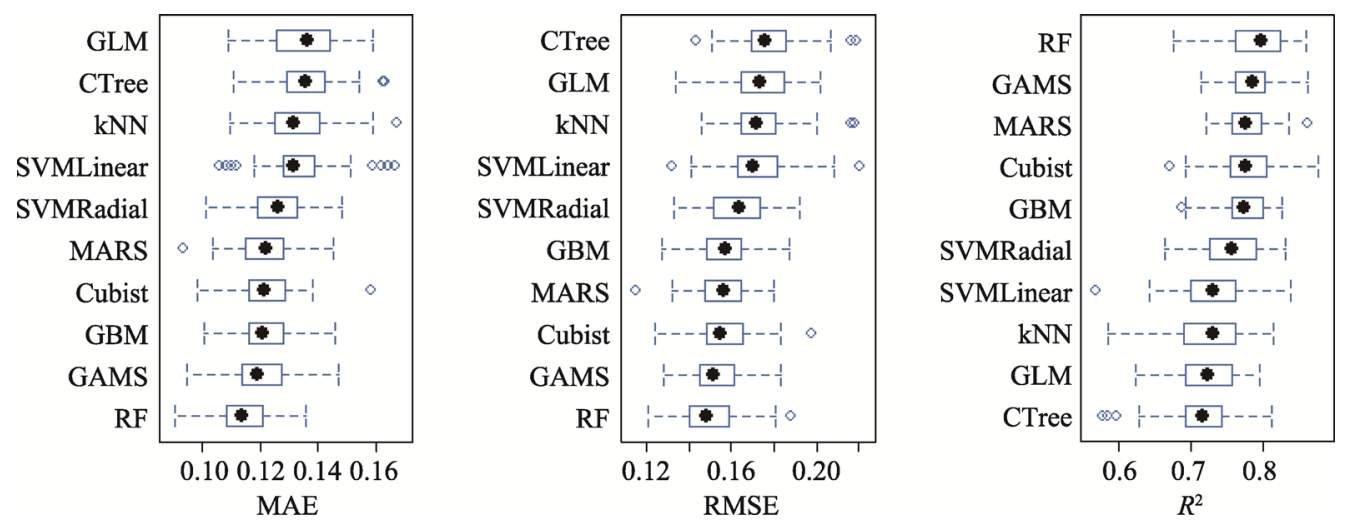

Figure 8 Boxplots of performance of machine learning methods in terms of the MAE, the RMSE, and $\mathrm{R}^{2}$ for the year 2015 
Table 8 Prediction errors and accuracy of machine learning methods

\begin{tabular}{|c|c|c|c|c|c|c|}
\hline \multirow{2}{*}{\multicolumn{2}{|c|}{ Method }} & \multicolumn{3}{|c|}{ 10-fold cross-validation } & \multirow{2}{*}{$\begin{array}{c}\text { Testing samples } \\
\mathrm{R}_{\text {test }}^{2}(\%) \\
\end{array}$} & \multirow{2}{*}{$\begin{array}{c}\text { Difference } \\
\mathrm{R}_{\mathrm{CV}}^{2}(\%)-\mathrm{R}_{\text {test }}^{2}(\%)\end{array}$} \\
\hline & & MAE (\%) & RMSE (\%) & $\mathrm{R}_{\mathrm{CV}}^{2}(\%)$ & & \\
\hline \multirow{3}{*}{ Linear } & GLM & 13.50 & 17.29 & 72.47 & 59.94 & +12.53 \\
\hline & GAMS & 12.03 & 15.37 & 78.13 & 68.72 & +9.41 \\
\hline & SVMLinear & 13.38 & 17.25 & 72.73 & 59.12 & +13.61 \\
\hline \multirow{3}{*}{ Nonlinear } & MARS & 12.11 & 15.52 & 77.90 & 70.78 & +7.12 \\
\hline & $k N N$ & 13.38 & 17.35 & 72.24 & 68.03 & +4.21 \\
\hline & SVMRadial & 12.55 & 16.27 & 75.53 & 70.02 & +5.51 \\
\hline \multirow{3}{*}{ Regression tree } & Cubist & 12.19 & 15.60 & 77.72 & 72.74 & +4.98 \\
\hline & $G B M$ & 12.16 & 15.68 & 77.40 & 70.83 & +6.57 \\
\hline & $R F$ & 11.39 & 14.97 & 79.17 & 77.68 & +1.49 \\
\hline
\end{tabular}

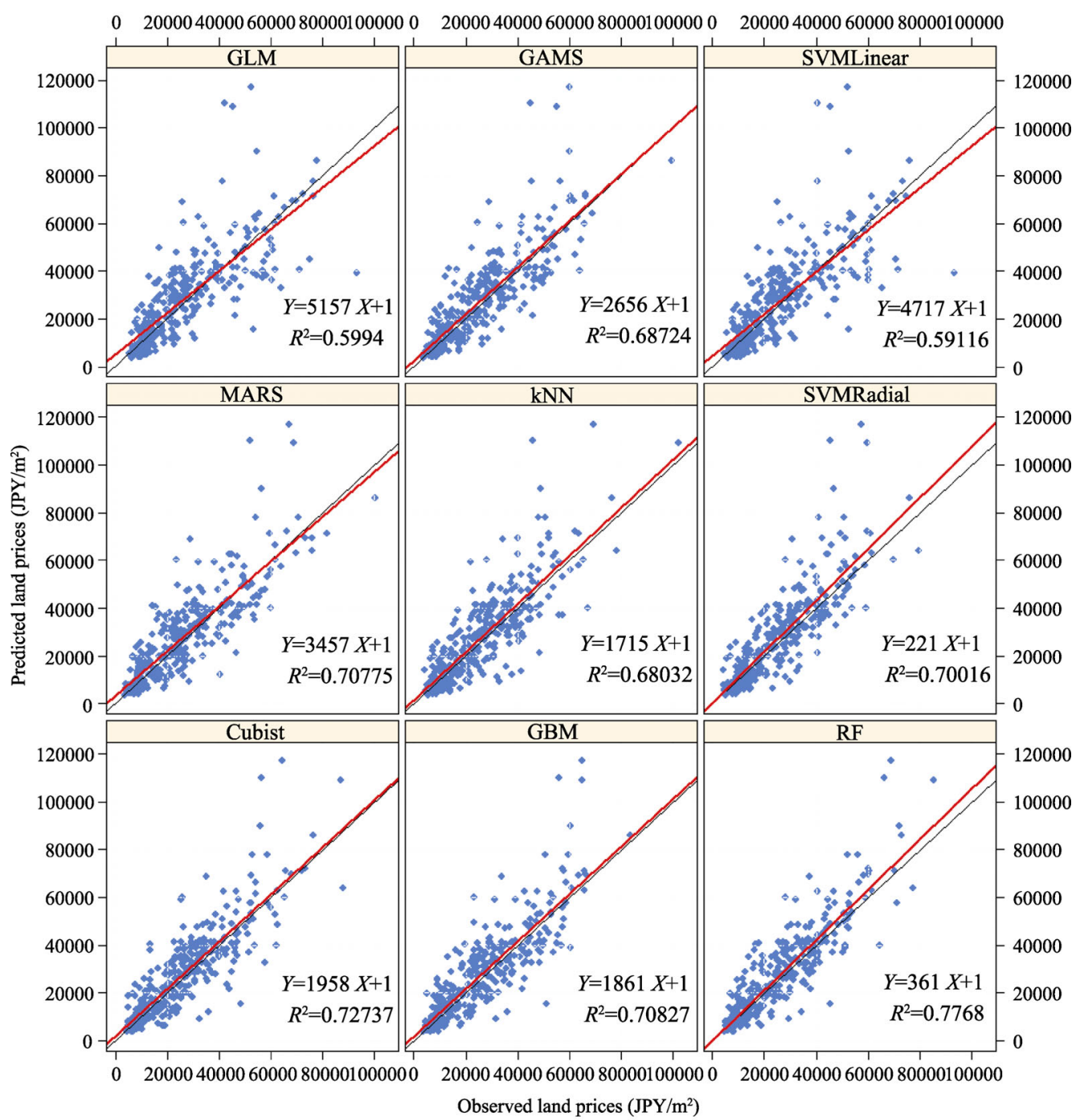

Figure 9 Observed land prices vs. predicted land prices for the year 2015 in the testing samples by different machine learning methods (ordered from left to right, up to down): (1) GLM: generalized linear model, (2) GAMS: generalized linear model using splines, (3) SVMLinear: support vector machines with linear kernel, (4) MARS: multivariate adaptive regression spline, (5) $k N N$ : k-nearest neighbors, (6) SVMRadial: support vector machines with radial basis function kernel, (7) Cubist, (8) GBM: stochastic gradient boosting and (9) $R F$ : random forest 
Figure 9 presents the observed land prices and the predicted land prices for the year 2015 for the testing samples using different machine learning methods. Figure 10 presents the resulting maps of the predicted land prices of 2015 in the study area using machine learning algorithms. The spatial resolution of all maps is $100 \mathrm{~m}$. All models show that land prices are spatially dependent on the distance to railways. The farther from railways the land, the higher the price. In remote areas around railways, the price ranges from $9500 \mathrm{JPY} / \mathrm{m}^{2}$ to $12,000 \mathrm{JPY} / \mathrm{m}^{2}$. Moreover, the most expensive land is located by all models within urban areas. Elevation was taken into consideration by most of the models except SVMRadial model that completely failed to consider topographic features, as it classified remote and mountainous areas in the southeastern (e.g., Mount Hiuchigatake with an elevation of 2356 m) and northern areas, for example, as high land price zones where the price
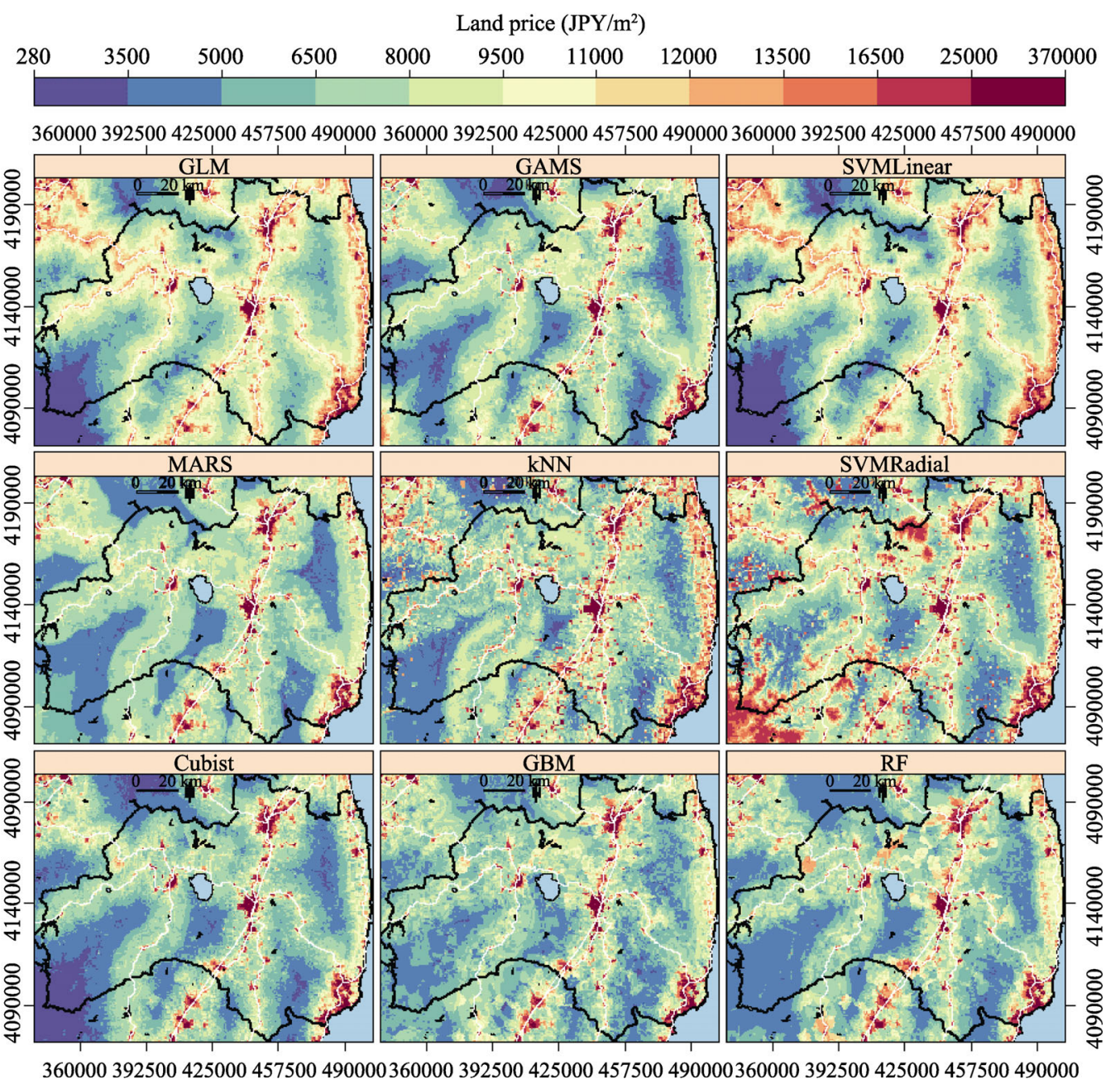

Figure 10 Land price maps for the year 2015 predicted from officially published land price observations using machine learning algorithms (ordered from left to right, up to down): (1) GLM: generalized linear model, (2) GAMS: generalized linear model using splines, (3) SVMLinear: support vector machines with linear kernel, (4) MARS: multivariate adaptive regression spline, (5) $k N N$ : k-nearest neighbors, (6) SVMRadial: support vector machines with radial basis function kernel, (7) Cubist, (8) GBM: stochastic gradient boosting and (9) RF: random forest 
exceeds 16,500 JPY $/ \mathrm{m}^{2}$. However, other models, including GAMS, MARS, $k N N$, and $G B M$, predicted medium (5000-9500 JPY $/ \mathrm{m}^{2}$ ) land prices for the summit region.

\subsection{Comparison of geostatistical analysis and machine learning modeling results}

For both analyses, we considered a similar set of training and testing samples to make the results of the different methods comparable. Consequently, we calculated the differences between the predicted land prices by the most robust machine learning methods (i.e., $R F$, Cubist, MARS, and GAMS) and the best-performing kriging based on the exponential model. The map results are illustrated in Figure 11. It can be seen that all maps have similar patterns
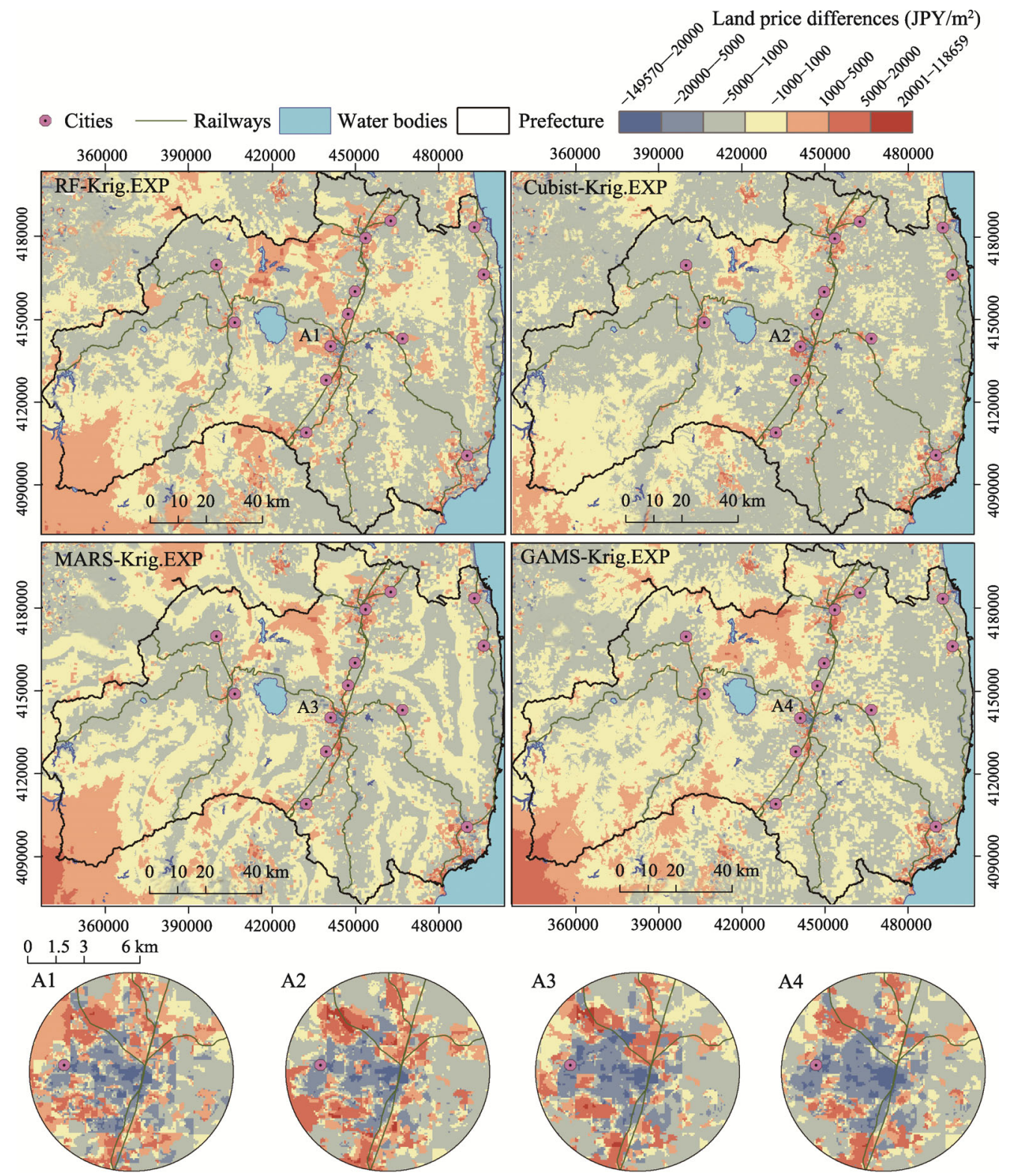

Figure 11 Maps of differences in the 2015 land prices between the best-performing machine learning algorithms: (1) RF: Random Forest, (2) Cubist, (3) MARS: Multivariate Adaptive Regression Spline and (4) GAMS: Generalized Linear Model using Splines and kriging exponential model. A1, A2, A3, and A4 show zoomed-in maps of Koriyama city and its outskirts 
across the study area, and the land price differences mostly range between $-5000 \mathrm{JPY} / \mathrm{m}^{2}$ and $5000 \mathrm{JPY} / \mathrm{m}^{2}$.

In general, the kriging model estimates high values for land prices in areas around railways and urban areas, which can explain the negative difference values ranging from -5000 $\mathrm{JPY} / \mathrm{m}^{2}$ and $-1000 \mathrm{JPY} / \mathrm{m}^{2}$ in these areas. However, positive values indicating lower estimations of land prices by kriging compared to machine learning methods (except Cubist) are scattered across the study area and generally spotted in mountainous areas. In the same figure, A1, A2, A3, and A4 show zoomed-in maps of Koriyama city, which illustrate sharp fluctuations in differences in land prices within urban areas. Land prices estimated by kriging in the city center where there is dense population and near railway stations tend to be classified as very high $\left(-149,570 \mathrm{JPY} / \mathrm{m}^{2}\right.$ to $\left.-20,000 \mathrm{JPY} / \mathrm{m}^{2}\right)$ and high $\left(-20,000 \mathrm{JPY} / \mathrm{m}^{2}\right.$ to $-5000 \mathrm{JPY} / \mathrm{m}^{2}$ ) compared to other methods. The farther from the city center, the lower the land price differences.

In terms of the quantitative results of the two approaches, we compared the area percentages of land price ranges in the prefecture and its subregions. Given their superiority compared to the other models of each approach, RF and krig.EXP are considered. Areas of designated evacuation zones resulting from the Fukushima Daiichi accident were excluded in this analysis. For the sake of simplicity, we classify the degree of prices according to the following classification: (1) low price: [500-6000 JPY $\left./ \mathrm{m}^{2}\right]$, (2) medium price: [6001-10,000 $\left.\mathrm{JPY} / \mathrm{m}^{2}\right]$, and (3) high price: $\left[10,001-320,000 \mathrm{JPY} / \mathrm{m}^{2}\right]$. The results are illustrated in Figure 12. In general, similarities between percentage values of RF and krig.EXP can be seen in most subregions and for almost all price ranges except for low-price ranges [4001-6000 $\left.\mathrm{JPY} / \mathrm{m}^{2}\right]$ and $\left[6001-12,000 \mathrm{JPY} / \mathrm{m}^{2}\right]$. In the whole prefecture, both distribution graphs of the area percentage of land price based on RF and krig.EXP follow a normal distribution. It can be seen that more than $80 \%$ of the land of the prefecture cost between $4000 \mathrm{JPY} / \mathrm{m}^{2}$ and $12,000 \mathrm{JPY} / \mathrm{m}^{2}$. Minamiaizu is the cheapest subregion in terms of the economic value of land, with approximately $95 \%$ of the land costing less than $10,000 \mathrm{JPY} / \mathrm{m}^{2}$. This can be attributed to the vast area of remote and mountainous areas, and likely the lack of an economic hotspot in the region. Neighboring subregions Aizu, Kennan, and Kenchu are not as cheap with $94 \%, 92 \%$, and $91 \%$ of land, respectively, below $12,000 \mathrm{JPY} / \mathrm{m}^{2}$. Based on RF, the subregions with a big share of areas of high-price land costing more than $10,000 \mathrm{JPY} / \mathrm{m}^{2}$ are Kenpoku (33\%), Iwaki (27\%), and Soso (26\%). However, based on krig.EXP, Soso has approximately $46 \%$ of high-price land, followed by Iwaki (42\%), and Kenpoku (41\%). Although there are significant differences between the results obtained (8\%-15\%), RF and krig.EXP managed to rank these subregions among the first three in terms of high-price land. These areas, as shown in Figures 1 and 4, are characterized by flat areas and cities serving as economic centers that are well connected by railways. More importantly, these subregions surround the evacuation zones declared after the Fukushima Daiichi accident where, as of May 2015, 113,983 persons were forced to leave their homes, of whom 67,782 continue to live as evacuees within the prefecture. It is likely that evacuees chose to flee to nearby cities located mainly in Soso, Iwaki, and Kenpoku. This perhaps influenced the price of land in these subregions. Overall, land prices in the prefecture are unevenly distributed with most of the medium and expensive land parcels located in the western area of the region character- 
ized by flat areas, the availability of multiple populated economic hotspots. The regional prices are influenced heavily by the proximity to railways within urban, rural, or remote areas.

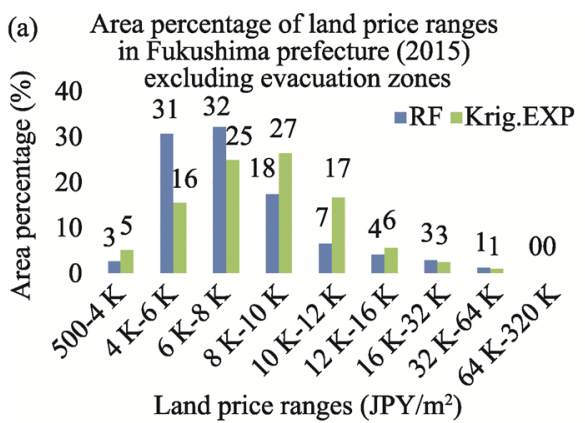

(c) Area percentage of land price ranges in the subregion of Iwaki (2015)

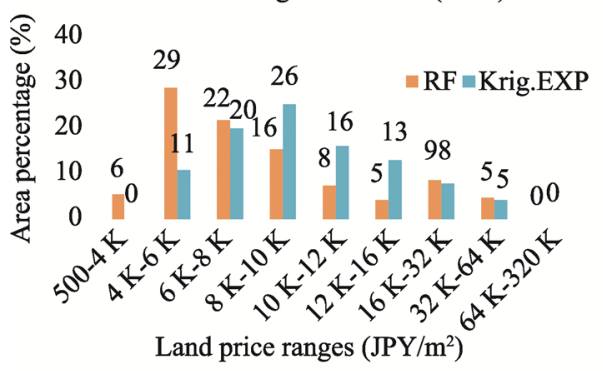

(e) Area percentage of land price ranges in the subregion of Kennan (2015)

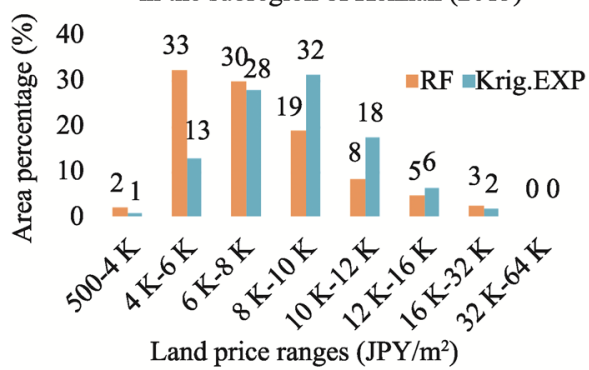

Area percentage of land price ranges
in the subregion of Minamiaizu (2015)

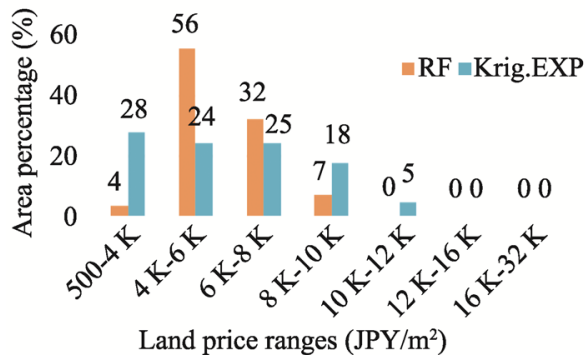

(b) Area percentage of land price ranges in the subregion of Aizu (2015)

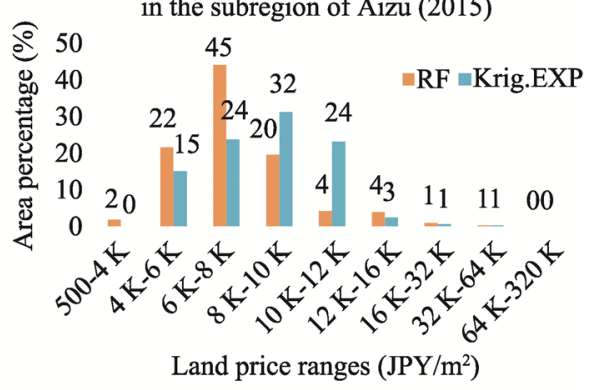

(d) Area percentage of land price ranges in the subregion of Kenchu (2015)

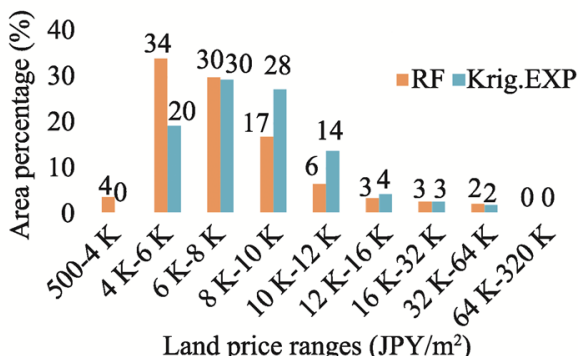

(f) Area percentage of land price ranges in the subregion of Kenpoku (2015)

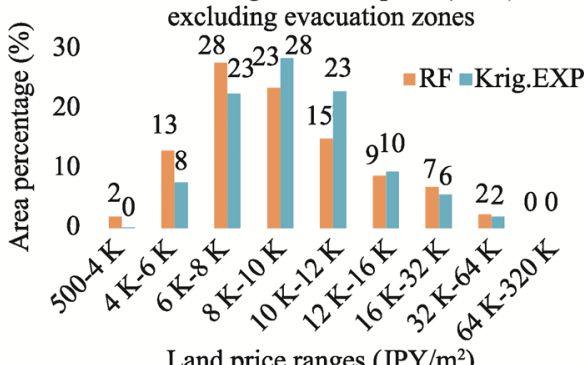

Land price ranges $\left(\mathrm{JPY} / \mathrm{m}^{2}\right)$
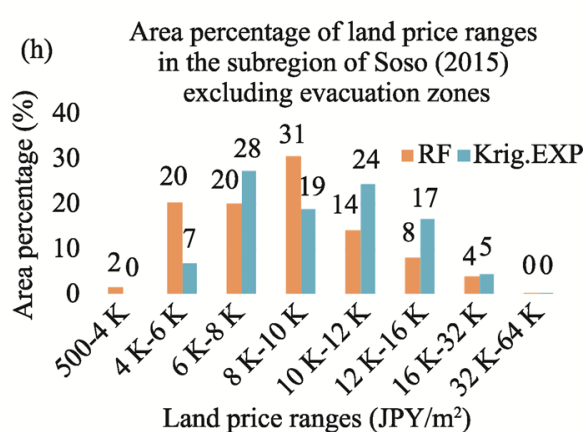

Land price ranges $\left(\mathrm{JPY} / \mathrm{m}^{2}\right)$

Figure 12 Area percentage of RF- and krig.EXP-based estimated land price for the year 2015 distributed by predefined ranges in Fukushima prefecture and its subregions 


\section{Discussion and conclusions}

\subsection{Discussion}

\subsubsection{Evaluation of the performance of the prediction methods}

In this study, we compared the results of the 2015 land prices estimation in Fukushima prefecture based on geostatistical models and various popular machine learning algorithms, which can be grouped into three categories: linear, nonlinear, and regression tree. We employed separate GIS-based frameworks to extract the predicted land price maps of each model and algorithm relying mainly on freely available GIS data and land price observations in the form of GIS point data published by local and prefectural governments. Based on the literature and considering the availability of data, we first selected the most likely factors influencing land prices in Fukushima prefecture, which has many cities and is known for its varied landscape with the elevation ranging from 0 to $2333 \mathrm{~m}$. These variables include population density, proximity to railway stations, elevation, and land use. We then performed a regression analysis to analyze the relationship between the selected explanatory variables and the log-transformed land prices. The results indicated that the selected factors explain the variation in land price of approximately $73 \%$ of the samples.

The first approach for estimating land economic values was based on geostatistical mathematical models of regression kriging, namely, exponential, Gaussian, and spherical. We determined the parameters of the semi-variograms of each model using the eye-fit method. To assess the estimation accuracy, we performed validation and cross-validation tests based on randomly selected training and testing samples representing $70 \%$ and $30 \%$ of the samples, respectively. Both tests showed that the exponential model (krig.EXP) gives slightly better results than the Gaussian model (krig.GAU) and the spherical model (krig.SPH), which concur with the conclusions reached by Tsutsumi et al. (2011) and Chica-Olmo et al. (2019). The second approach for predicting land prices was to employ nine popular ML algorithms split into three categories: (1) linear (GLM, GAMS, and SVMLinear), (2) nonlinear (MARS, kNN, and SVMRadial), and (3) regression tree (Cubist, GBM, and RF). The performance of each algorithm was assessed based on the calculation of the MAE, the RMSE, and $\mathrm{R}^{2}$ following 10-fold cross-validation based on the same set of training/testing data used for the previous approach. According to the results, regression tree algorithms performed better; the RF was clearly superior in terms of all errors and accuracy indicators. This result coincides with the outcome of previous studies, such as the ones carried out by Antipov and Pokryshevskaya (2012) and Schernthanner et al. (2016). Empirically, compared to the lowest RMSE of krig.EXP (15.1\%), only the regression tree's RF performed better, whereas all nonlinear and linear models performed worse.

For both approaches, maps of the 2015 spatial variation of estimated land prices in Fukushima prefecture were extracted. The resulting maps showed a strong influence of railways on land prices in the region, which was in agreement with the conclusions of Zhuang and Zhao (2014) and Kanasugi and Ushijima (2018). The closer to railways and the stations, the more expensive the land price. Additionally, all maps showed high prices in urban areas ranging from $12,000 \mathrm{JPY} / \mathrm{m}^{2}$ to $370,000 \mathrm{JPY} / \mathrm{m}^{2}$. However, all maps based on geostatistical models and five of the ML methods (GLM, SVMlinear, kNN, Cubist, and RF) showed lower 
values in remote and mountainous areas. GAMS- and MARS-based maps either underestimated or overestimated land values in mountainous areas mainly in the southwest of the region known for its high mountain peaks reaching a maximum altitude of $2564 \mathrm{~m}$. The GBM map showed lower values in mountainous areas yet dispersed in uniform patterns. SVMRadial completely failed to map land prices in these areas as it overestimated the value reaching $370,000 \mathrm{JPY} / \mathrm{m}^{2}$. The next step was to extract maps of land value differences between the best-performing ML algorithms (RF, GAMS, Cubist, and MARS) and the regression kriging exponential model (krig.EXP). Through a qualitative visual inspection of these maps, we concluded that the land price differences range between $-5000 \mathrm{JPY} / \mathrm{m}^{2}$ and $5000 \mathrm{JPY} / \mathrm{m}^{2}$. Huge positive and negative differences are found mainly in urban areas.

\subsubsection{Limitations and suggested future directions}

This study is a contribution to the growing literature on the estimation and the mapping of land prices at the regional level. To the best of our knowledge, it is the first of its kind in the study area and one of the few papers to compare empirically and visually estimated land prices using regression kriging and typical ML algorithms of the likes of RF, SVM, and kNN. However, some problems remain unsolved and should be addressed in future studies. First, we recognize that the selection of explanatory variables is very important when estimating and mapping land prices. However, due to availability issues or high costs, acquiring spatial data covering a wide area is not always possible. New methods of acquiring data remain to be considered. Moreover, relying only on published literature to select potential factors might not always be fruitful as these variables depend significantly on the settings of the target area. Thus, conducting a transparent multi-criteria analysis based on surveys among local experts is an option to be considered. Second, the developed frameworks are based only on one model for an entire prefecture, which generated overestimated land prices in urban areas and underestimated values in suburban areas in the case of geostatistical models. The accuracy of these models' results can be further improved by combining multiple models to create hybrid models of the sort of GWR kriging suggested by Harris et al. (2010) or ensemble learning algorithms as introduced by Dietterich (2000) and explained further by Zhou (2012).

\subsection{Conclusions}

Having accurate and updated maps of land prices aids market actors in making decisions. These maps constitute an essential reference for planning authorities and key investors before starting any regional-level project. In Japan, maps of this kind are not publicly available; most of the real estate companies do not share their precise maps publicly, because their extraction requires a considerable amount of time and resources. Luckily, every year the Japanese local government, as well as the prefectural governments, releases observation samples of land prices as a result of separate field surveys. Though limited and dispersed, these observations constitute a valuable asset of information. In recent years, multiple models have been applied to estimate and to map land economic values with a considerable share of them based on hedonic models; focusing mainly on estimating residential prices in urban areas. This study, however, employed geostatistical methods and machine learning algorithms to estimate and to map general land prices of 2015 at the macro-scale in Fukushima prefecture. 
The primary purpose was to compare quantitatively and qualitatively all these models in terms of the predictions' accuracy errors.

As one of the geostatistical methods, regression kriging was applied based on three mathematical models (krig.EXP, krig.GAU, krig.SPH) to predict land prices. The validation and cross-validation results show that the exponential model (krig.EXP) gives slightly better results. For ML algorithms, we empirically compared nine algorithms grouped into three categories: linear (GLM, GAMS, SVMLinear), nonlinear (MARS, kNN, SVMRadial), and regression tree (Cubist, GBM, and RF). Results of the prediction accuracy based on the RMSE, the MAE, and $\mathrm{R}^{2}$ show the superiority of the regression trees models to estimate accurately land prices, while linear models were the worst models. Among all methods, RF was the most robust method for estimating land prices reliably. The final ranking of all methods according to the cross-validation RMSE in descending order is RF (14.97\%), krig.EXP (15.1\%), GAMS (15.37\%), krig.SPH (15.5\%), MARS (15.52\%), krig.GAU (15.75\%), Cubist (15.6\%), GBM (15.68\%), SVMRadial (16.27\%), SVMLinear (17.25\%), GLM (17.29\%), and kNN (17.35\%). A qualitative comparison of the maps' results of the most accurate methods indicates that kriging highly estimates land prices in mountainous areas, and the outskirts of urban areas, and predicts lower values within city centers where population density is high. It can be concluded that railways affect the price of land heavily. All models demonstrated this fact, and the differences in the values obtained by subtracting the RF, Cubist, MARS, and GAMS values from the kriging values are medium around railways and quasi-equal beyond. Although geostatistical models and machine learning algorithms can efficiently estimate land prices, the accuracy of these models' results can be further improved by combining multiple models to create hybrid models and ensemble learning algorithms.

\section{Acknowledgments}

The authors would like to thank the editor and the three anonymous reviewers for their constructive comments, which helped to improve the quality of the manuscript.

\section{References}

Adegoke O J, 2014. Critical factors determining rental value of residential property in Ibadan metropolis, Nigeria. Property Management, 32(3): 224-240. doi: 10.1108/PM-05-2013-0033.

Antipov E A, Pokryshevskaya E B, 2012. Mass appraisal of residential apartments: An application of random forest for valuation and a CART-based approach for model diagnostics. Expert Systems with Applications, 39(2): 1772-1778. doi: 10.1016/j.eswa.2011.08.077.

Arnott R J, Lewis F D, 1979. The transition of land to urban use. Journal of Political Economy, 87(1): 161-169. doi: $10.1086 / 260744$.

Bourassa S, Cantoni E, Hoesli M, 2010. Predicting house prices with spatial dependence: A comparison of alternative methods. Journal of Real Estate Research, 32(2): 139-159. doi: 10.5555/rees.32.2.115423724383157x.

Breiman L, 2001. Random forests. Machine Learning, 45(1): 5-32. doi: 10.1023/A:1010933404324.

Brunsdon C, Fotheringham S, Charlton M, 1998. Geographically weighted regression. Journal of the Royal Statistical Society: Series D (The Statistician), 47(3): 431-443. doi: 10.1111/1467-9884.00145.

Caplin A, Chopra S, Leahy J V et al., 2008. Machine learning and the spatial structure of house prices and housing returns. ID 1316046, SSRN Scholarly Paper, 14 December. Rochester, NY: Social Science Research Net- 
work. Available at: https://papers.ssrn.com/abstract=1316046 (accessed 8 February 2019).

Capozza D R, Helsley R W, 1989. The fundamentals of land prices and urban growth. Journal of Urban Economics, 26(3): 295-306. doi: 10.1016/0094-1190(89)90003-X.

Capozza D R, Helsley R W, Mills E S, 1986. Urban growth and the price of land [D]. University of British Columbia, Faculty of Commerce and Business Administration.

Cellmer R, Belej M, Zrobek S et al., 2014. Urban land value maps: A methodological approach. Geodetski Vestnik, 58(3): 535-551. doi: 10.15292/geodetski-vestnik.2014.03.535-551.

Chica-Olmo J, 2007. Prediction of housing location price by a multivariate spatial method: Cokriging. Journal of Real Estate Research, 29(1): 91-114. doi: 10.5555/rees.29.1.06254n3806648g9w.

Chica-Olmo J, Cano-Guervos R, Chica-Rivas M, 2019. Estimation of housing price variations using spatio-temporal data. Sustainability, 11(6): 1551. doi: 10.3390/su11061551.

Clapp J M, Nanda A, Ross S L, 2008. Which school attributes matter? The influence of school district performance and demographic composition on property values. Journal of Urban Economics, 63(2): 451-466. doi: 10.1016/j.jue.2007.03.004.

Crespo R, Grêt-Regamey A, 2013. Local hedonic house-price modelling for urban planners: Advantages of using local regression techniques. Environment and Planning B: Planning and Design, 40(4): 664-682. doi: $10.1068 / \mathrm{b} 38093$.

Derdouri A, Murayama Y, 2018. Onshore wind farm suitability analysis using GIS-based analytic hierarchy process: A case study of Fukushima Prefecture, Japan. Geoinformatics \& Geostatistics: An Overview. doi: 10.4172/2327-4581.S3-005.

Espey M, Owusu-Edusei K, 2001. Neighborhood parks and residential property values in Greenville, South Carolina. Journal of Agricultural and Applied Economics, 33(3): 487-492. doi: 10.1017/S1074070800020952.

Gu J, Zhu M, Jiang L, 2011. Housing price forecasting based on genetic algorithm and support vector machine. Expert Systems with Applications, 38(4): 3383-3386. doi: 10.1016/j.eswa.2010.08.123.

Harris P, Charlton M, Fotheringham A S, 2010. Moving window kriging with geographically weighted variograms. Stochastic Environmental Research and Risk Assessment, 24(8): 1193-1209. doi: 10.1007/s00477-010-0391-2.

Hengl T, 2009. A Practical Guide to Geostatistical Mapping. Hengl.

Hengl T, Heuvelink G B M, Rossiter D G, 2007. About regression-kriging: From equations to case studies. Computers \& Geosciences, 33(10). Spatial Analysis: 1301-1315. doi: 10.1016/j.cageo.2007.05.001.

Hilal M, Martin E, Piguet V, 2016. Prediction of the purchase cost of agricultural land: The example of Côte-d'Or, France. Land Use Policy, 52: 464-476. doi: 10.1016/j.landusepol.2016.01.005.

$\mathrm{Hu}$ S, Yang S, Li W et al., 2016. Spatially non-stationary relationships between urban residential land price and impact factors in Wuhan city, China. Applied Geography, 68: 48-56. doi: 10.1016/j.apgeog.2016.01.006.

Inoue R, Kigoshi N, Shimizu E, 2007. Visualization of spatial distribution and temporal change of land prices for residential use in Tokyo 23 wards using spatio-temporal kriging. In: Proceedings of 10th International Conference on Computers in Urban Planning and Urban Management, 2007, 1-11.

Kanasugi H, Ushijima K, 2018. The impact of a high - speed railway on residential land prices. Papers in Regional Science, 97(4):1305-1335. doi: 10.1111/pirs.12293.

Kawaguchi D, Yukutake N, 2017. Estimating the residential land damage of the Fukushima nuclear accident. Journal of Urban Economics, 99: 148-160. doi: 10.1016/j.jue.2017.02.005.

Kiel K A, Zabel J E, 2008. Location, location, location: The 3L Approach to house price determination. Journal of Housing Economics, 17(2): 175-190. doi: 10.1016/j.jhe.2007.12.002.

Kim B, Kim T, 2016. A study on estimation of land value using spatial statistics: Focusing on real transaction land prices in Korea. Sustainability, 8(3): 203. doi: 10.3390/su8030203.

Kok N, Monkkonen P, Quigley J M, 2014. Land use regulations and the value of land and housing: An intra-metropolitan analysis. Journal of Urban Economics, 81: 136-148. doi: 10.1016/j.jue.2014.03.004.

Krige D G, 1951. A statistical approach to some basic mine valuation problems on the Witwatersrand. Journal of the Southern African Institute of Mining and Metallurgy, 52(6): 119-139.

Kuhn M, 2008. Building predictive models in R using the caret package. Journal of Statistical Software, 28(1): 
1-26. doi: 10.18637/jss.v028.i05.

Kuhn M, Johnson K, 2013. Applied Predictive Modeling. New York: Springer-Verlag. Available at: https://www.springer.com/gp/book/9781461468486 (accessed 8 February 2019).

Kuntz M, Helbich M, 2014. Geostatistical mapping of real estate prices: An empirical comparison of kriging and cokriging. International Journal of Geographical Information Science, 28(9): 1904-1921. doi: 10.1080/13658816.2014.906041.

Liu Y, Zheng B, Huang L et al., 2007. Urban residential land value analysis: Case Danyang, China. Geo-spatial Information Science, 10(3): 228-234. doi: 10.1007/s11806-007-0066-4.

Löchl M, 2006. Real estate and land price models for the Greater Zurich application of UrbanSim. Working Paper. ETH, Eidgenössische Technische Hochschule Zürich, IVT, Institut für Verkehrsplanung und Transportsysteme. Available at: https://www.research-collection.ethz.ch/handle/20.500.11850/23502?show=full (accessed 8 February 2019).

Luo J, Wei Y D, 2004. A geostatistical modeling of urban land values in Milwaukee, Wisconsin. Geographic Information Sciences, 10(1): 49-57. doi: 10.1080/10824000409480654.

Ministry of Internal Affairs and Communications (MIAC), 2016. Statistical Handbook of Japan. Statistics Bureau Ministry of Internal Affairs and Communications Japan. Available at: http://www.stat.go.jp/english/data/ handbook/pdf/ 2016all.pdf (accessed 23 December 2017).

Mostafa M M, 2018. A spatial econometric analysis of residential land prices in Kuwait. Regional Studies, Regional Science, 5(1): 290-311. doi: 10.1080/21681376.2018.1518154.

Murakami J, 2018. The Government Land Sales programme and developers' willingness to pay for accessibility in Singapore, 1990-2015. Land Use Policy, 75: 292-302. doi: 10.1016/j.landusepol.2018.03.050.

Nishimura Y, Oikawa M, 2017. The effect of nuclear accidents on land prices: Evidence from Fukushima-Daiichi in Japan. ID 3057221, SSRN Scholarly Paper, 23 October. Rochester, NY: Social Science Research Network. Available at: https://papers.ssrn.com/abstract=3057221 (accessed 18 June 2019).

Palma M, Cappello C, De Iaco S et al., 2019. The residential real estate market in Italy: A spatio-temporal analysis. Quality \& Quantity, 53(4): 2451-2472. doi: 10.1007/s11135-018-0768-8.

Park B, Bae J K, 2015. Using machine learning algorithms for housing price prediction: The case of Fairfax County, Virginia housing data. Expert Systems with Applications, 42(6): 2928-2934. doi: 10.1016/j.eswa. 2014.11.040.

Pebesma E J, 2004. Multivariable geostatistics in S: The gstat package. Computers \& Geosciences, 30(7): 683-691. doi: 10.1016/j.cageo.2004.03.012.

Ratle F, Pozdnoukhov A, Demyanov V et al., 2010. Spatial data analysis and mapping using machine learning algorithms. In: Advanced Mapping of Environmental Data. John Wiley \& Sons, Ltd, 95-148. doi: 10.1002/9780470611463.ch4.

Ridgeway G, 2005. Generalized boosted models: A guide to the gbm package. In: 2005.

Sampathkumar V, Santhi M H, Vanjinathan J, 2015. Forecasting the land price using statistical and neural network software. Procedia Computer Science, 57. 3rd International Conference on Recent Trends in Computing 2015 (ICRTC-2015): 112-121. doi: 10.1016/j.procs.2015.07.377.

Sasaki M, Yamamoto K, 2018. Hedonic price function for residential area focusing on the reasons for residential preferences in Japanese metropolitan areas. Journal of Risk and Financial Management, 11(3): 39. doi: $10.3390 /$ jrfm 11030039 .

Schernthanner H, Asche H, Gonschorek J et al., 2016. Spatial modeling and geovisualization of rental prices for real estate portals. In: Gervasi O, Murgante B, Misra S et al. (eds.), Computational Science and Its Applications - ICCSA 2016, 120-133. Lecture Notes in Computer Science. Springer International Publishing.

Shimizu C, Diewert W E, Nishimura K G et al., 2015. Estimating quality adjusted commercial property price indexes using Japanese REIT data. Journal of Property Research, 32(3): 217-239. doi: 10.1080/09599916. 2015.1059875.

Shimizu C, Nishimura K G, 2007. Pricing structure in Tokyo metropolitan land markets and its structural changes: Pre-bubble, bubble, and post-bubble periods. The Journal of Real Estate Finance and Economics, 35(4): 
475-496. doi: 10.1007/s11146-007-9052-8.

Szymanowski M, Kryza M, Spallek W, 2013. Regression-based air temperature spatial prediction models: An example from Poland. Meteorologische Zeitschrift, 577-585. doi: 10.1127/0941-2948/2013/0440.

Tanaka K, Managi S, 2016. Impact of a disaster on land price: Evidence from Fukushima nuclear power plant accident. The Singapore Economic Review, 61(1): 1640003. doi: 10.1142/S0217590816400038.

Tegou L-I, Polatidis H, Haralambopoulos D A, 2010. Environmental management framework for wind farm siting: Methodology and case study. Journal of Environmental Management, 91(11): 2134-2147. doi: 10.1016/j.jenvman.2010.05.010.

Tobler W R, 1970. A computer movie simulating urban growth in the Detroit region. Economic Geography, 46(Suppl.1): 234-240. doi: 10.2307/143141.

Tsujikawa N, Tsuchida S, Shiotani T, 2016. Changes in the factors influencing public acceptance of nuclear power generation in Japan since the 2011 Fukushima Daiichi nuclear disaster. Risk Analysis, 36(1): 98-113. doi: $10.1111 /$ risa. 12447.

Tsutsumi M, Shimada A, Murakami D, 2011. Land price maps of Tokyo Metropolitan Area. Procedia Social and Behavioral Sciences 21. International Conference: Spatial Thinking and Geographic Information Sciences 2011: 193-202. doi: 10.1016/j.sbspro.2011.07.046.

Wang Q, M'Ikiugu M M, Kinoshita I et al., 2016. GIS-based approach for municipal renewable energy planning to support post-earthquake revitalization: A Japanese case study. Sustainability, 8(7): 703 . doi: $10.3390 /$ su8070703.

Wang X, Wen J, Zhang Y et al., 2014. Real estate price forecasting based on SVM optimized by PSO. Optik, 125(3): 1439-1443. doi: 10.1016/j.ijleo.2013.09.017.

Wen H, Goodman A C, 2013. Relationship between urban land price and housing price: Evidence from 21 provincial capitals in China. Habitat International, 40: 9-17. doi: 10.1016/j.habitatint.2013.01.004.

Wen H, Chu L, Zhang J et al., 2018. Competitive intensity, developer expectation, and land price: Evidence from Hangzhou, China. Journal of Urban Planning and Development, 144(4): 04018040. doi: 10.1061/(ASCE)UP.1943-5444.0000490.

Yamane F, Ohgaki H, Asano K, 2013. The immediate impact of the Fukushima Daiichi accident on local property values. Risk Analysis, 33(11): 2023-2040. doi: 10.1111/risa.12045.

Zhuang X, Zhao S, 2014. Effects of land and building usage on population, land price and passengers in station areas: A case study in Fukuoka, Japan. Frontiers of Architectural Research, 3(2): 199-212. doi: 10.1016/j.foar.2014.01.004. 